\title{
Functionalization of microstructured open-porous bio-ceramic scaffolds with human fetal bone cells
}

${ }^{1}$ Franziska Krauss Juillerat ${ }^{\S}$, ${ }^{2}$ Françoise Borcard ${ }^{\S}$, ${ }^{2}$ Davide Staedler, ${ }^{3}$ Corinne Scaletta, ${ }^{3}$ Lee Ann Applegate, ${ }^{2}$ Horacio Comas, ${ }^{1}$ Ludwig J. Gauckler, ${ }^{2}$ Sandrine Gerber-Lemaire, ${ }^{4}$ Lucienne Juillerat-Jeanneret*, ${ }^{1}$ Urs T. Gonzenbach*

§ These two authors participated equally to this work.

${ }^{1}$ Nonmetallic Inorganic Materials, ETHZ, CH-8093 Zurich, Switzerland; ${ }^{2}$ Institute of Chemical Sciences and Engineering, EPFL, CH-1015, Lausanne, Switzerland; ${ }^{3}$ Department of Musculoskeletal Medicine, Cellular Therapy Unit, University Hospital, CH-1011 Lausanne, Switzerland; ${ }^{4}$ Institute of Pathology, CHUV-UNIL, CH-1011 Lausanne, Switzerland.

Running title: Biomaterials for hard tissue engineering with human fetal bone cells

*Corresponding authors:

- Dr Urs T. Gonzenbach; Nonmetallic Inorganic Materials; HCI G531; Wolfgang-PauliStrasse 10; ETH Zurich; CH-8093 Zurich; Switzerland

Phone: +41 44632 71 84; Fax:+41 4463211 32; e-mail: urs.gonzenbach@mat.ethz.ch

- Dr Lucienne Juillerat; Centre Hospitalier Universitaire Vaudois-University of Lausanne (CHUV-UNIL); Institute of Pathology; rue du Bugnon 25; CH-1011 Lausanne; Switzerland Phone: +41 2131471 73; Fax: +41 2131471 15; e-mail: lucienne.juillerat@chuv.ch 


\begin{abstract}
Bone substitute materials permissive for trans-scaffold migration and in-scaffold survival of human bone-derived cells are mandatory to develop cell-engineered permanent implants to repair bone defects. In this study, we evaluated the influence on human bone-derived cells of the material composition and microstructure of foam scaffolds made from calcium aluminate using a direct foaming method allowing wide-range tailoring of the microstructure for pore size and pore openings. Human fetal osteoblasts attached to the scaffolds, migrated across the entire materials depending on the scaffold pore size, colonized and survived in the porous material for at least 6 weeks. The long-term biocompatibility of the scaffold material for human cells was evidenced by in scaffold determination of cell metabolic activity using a modified MTT assay, a repeated WST-1 assay and scanning electron microscopy. Finally, we demonstrated that the fetal cells can be covalently bound to the scaffolds using biocompatible click chemistry, thus enhancing the rapid adhesion of the cells to the scaffolds. Thus, the different microstructures of the foams influenced the migratory potential of the cells, but not cell viability, and the scaffolds were permissive for covalent biocompatible chemical binding of the cells to the materials, allowing either localized or widespread cellularization of the scaffolds for cell-engineered implants.
\end{abstract}

Key words : permanent bone graft / biocompatibility / ceramic structure / open pores / cell migration / human fetal osteoblasts / biocompatible click-chemistry 


\section{Introduction}

The demand of materials for the repair and substitution of damaged tissues, including bone tissue, is increasing. Presently the standard treatment for bone defects is autologous iliac crest bone grafting, but the need of a second surgery with its increased risk of infections, possible donor site morbidity, and also financial aspects, ask for the development of synthetic bone graft materials presently used in only about $15 \%$ of the cases. ${ }^{1}$ Therefore the development of scaffolds able to integrate in bone tissue and support bone regeneration across defects that are too large to heal naturally or when normal healing process is compromised ${ }^{2}$ is mandatory for the success of reconstructive strategies for the treatment of critical-size bone defects. ${ }^{3,4}$

To achieve these requirements two possibilities can be envisioned. The bone substitute is biodegradable and transitory and will be replaced by tissue from the organ, an approach which was mainly developed up to now. However, for large bone defects, such as seen in major bone loss, such a strategy is not always possible and permanent implants are requested which can be prepared into shapes reproducing the shape of the bone to be replaced and improve their integration in the tissue of implantation by promoting the interface continuity. These permanent implants must also be permissive for the growth of bone cells which should first functionalize the implant, providing cell-engineered implant materials, prior to implantation to improve its integration at the implantation site. The understanding of bone tissue structure allows for rational material design, able of mimicking the tissue structure and the specific biochemistry of bone. Bone is a highly organized tissue that assembles from nano- to macroscales to produce complex structural interconnected porous networks. Therefore, the development of permanent bone substitute materials presenting trans-scaffold channels permissive for migration and in-scaffold survival of human bone-derived cells are mandatory for ultimately develop a functional bone tissue for permanent implants to repair large bone defects. Such materials have also to ultimately support the formation of differentiated bone 
cell structures inside the permanent implant. To obtain a physical support for permanent artificial bone tissue, synthetic, porous scaffolds must therefore be produced from inert biocompatible materials, such as alumina or titanium. ${ }^{5-7}$

To develop permanent implants which have been engineered with human bone cells prior to implantation for the repair of human bone defects, histocompatibility problems of the cells of the implant with the recipient of the graft must also be considered. Human fetal cells have an interesting potential for therapeutic use for tissue engineering and regeneration, including bone tissue engineering, due to their rapid growth rate and their ability to differentiate in vitro into mature cells as well as their histocompatibility, ${ }^{8,9}$ eliminating the need for anti-graft rejection medication of the patients. However, presently, the developments for artificial bone implants performed with human fetal cells have used materials that were designed to be biodegradable. ${ }^{10-12}$

In the present study, our goals were to develop calcium aluminate scaffolds suitable for permanent bone replacement, displaying an open-porous channel microstructure allowing the engraftment and migration through the ceramics of human histocompatible bone-derived cells. The calcium aluminate scaffolds were produced from a modified direct foaming method ${ }^{13-19}$ which allows the production of macroporous scaffolds which are tailorable in pore size, microstructure and shape. In particular we aimed to determine the optimal pore sizes to allow survival and migration of these human bone-derived cells across the scaffolds. Therefore, we investigated the interaction of calcium aluminate scaffolds of varying composition and pore sizes first with human osteosarcoma cells in order to select the ceramic composition displaying optimal pore sizes and pore opening sizes, then with primary human fetal osteoblasts as models for histocompatible human bone-derived cells. We also determined whether the adhesion of the human fetal bone cells to these scaffolds can be improved by chemical functionalization using a biocompatible click-chemistry based covalent approach. 


\section{Experimental Procedures}

\section{Preparation and characterization of the scaffolds}

\section{Preparation of the scaffold materials}

The particles used to prepare the suspensions were a high-purity $\alpha-\mathrm{Al}_{2} \mathrm{O}_{3}$ powder (HPA0.5w/MgO, Ceralox, Tucson, AZ) with an average particle size of $200 \mathrm{~nm}$. The short chain amphiphile selected to in-situ modify the alumina particles was propyl gallate (Fluka AG, Buchs, Switzerland). Further chemicals used in the present study were hydrochloric acid, sodium hydroxide (both Titrisol, Merck, Germany) and deionized water (18.2 M $/ \mathrm{cm})$. To consolidate the wet scaffolds, the calcium aluminate cement "CA-270" (Almatis GmbH, Ludwigshafen/Rhein, Germany) and the setting accelerator lithium carbonate (Fluka AG, Buchs, Switzerland) were used.

Alumina suspensions were prepared by stepwise addition of alumina powder to an aqueous solution containing $27 \mathrm{mM} \mathrm{NaOH}$ and $22 \mathrm{mM}$ propyl gallate. The suspension solids loading was initially fixed to 50 vol\%. Homogenization and deagglomeration of the suspensions were carried out on a ball mill for $18 \mathrm{~h}$ using polyethylene milling bottles $(1 \mathrm{~L})$ and alumina balls (10 $\mathrm{mm}$ in diameter, weight ratio balls to suspension $\approx 2: 1$ ). After ball milling, three different suspensions were prepared as follows: the propyl gallate content was adjusted to 2, 1.2 or 1 wt\% to the amount of alumina particles by dissolving it in a $\mathrm{NaOH}$ aqueous solution displaying a pH higher than 10 . These solutions were then added drop-wise to the ball-milled suspensions under stirring to avoid local particle agglomeration. Finally, the pH was set to 9.9 and the solids loadings were adjusted to the respective volume fractions (12.7, 32.9 or 10.8 vol\%) by adding water to the suspensions. Immediately before the foaming step, the desired amount of cement powder (33.7, 4.3 or 26.3 vol\%) and the setting accelerator lithium carbonate (5 wt\% to the amount of cement) were added to the suspensions and dispersed under stirring. 
Foaming of the cement containing suspensions was carried out using a household food processor (Kenwood, Major Classic) at maximum power level (800 W) during $3 \mathrm{~min}$. The wet foams were then filled into cylindrical moulds, $10 \mathrm{~cm}$ in diameter and $5 \mathrm{~cm}$ high, and left to set at ambient temperature overnight in a moist atmosphere to prevent drying. After setting and drying, the specimens were sintered in an electrical furnace (HT 40/16, Nabertherm, Germany) at $1575^{\circ} \mathrm{C}$ for $2 \mathrm{~h}$. The heating rate was controlled to $1^{\circ} \mathrm{C} / \mathrm{min}$ and the cooling rate was controlled to $3^{\circ} \mathrm{C} / \mathrm{min}$. The sintered samples were then drilled into cylinders of $10 \mathrm{~mm}$ in diameter and $2 \mathrm{~mm}$ high, ultrasonicated in ethanol and acetone and dried at $110^{\circ} \mathrm{C}$.

\section{Characterization of the scaffold microstructure}

The porosity was determined by weighing a defined volume of a scaffold sample, and calculating the air content using the following formula: air content (vol\%) = (1$\left.\rho_{\text {measured }} / \rho_{\text {dense }}\right) \cdot 100 \%$, whereas $\rho=$ density in $\mathrm{g} / \mathrm{cm}^{3}$. To define the diameters of the pores and pore-openings, scanning electron microscopy (SEM) (LEO 1530, Zeiss Oberkochen in SE2 mode and at low magnifications) micrographs were analyzed using the software Linear Intercept (TU Darmstadt, Germany), defining 250 intersections on 5 representative images.

\section{Chemistry}

Commercial reagents (Fluka, Aldrich, VWR, Switzerland) were used without further purification. Anhydrous solvents were obtained by filtration (PureSolv MD Series, Innovative Technology). TLCs for reaction monitoring were performed on Merck silica gel 60 F254 plates, and spots were revealed with UV light and reaction with $\mathrm{KMnO}_{4}$ or ninhydrine. IR spectra were recorded on a Perkin-Elmer-1420 spectrometer. ${ }^{1} \mathrm{H}$ NMR spectra were recorded on a Bruker-ARX-400 spectrometer (400 MHz) using MeOD as solvent and calibrated using the solvent's residual signal at $3.31 \mathrm{ppm}$ as an internal reference. ${ }^{13} \mathrm{C}$ NMR spectra were 
recorded on a Bruker-ARX-400 spectrometer (100.6 MHz) using MeOD as solvent and calibrated using the solvent's residual signal at $49.0 \mathrm{ppm}$ as an internal reference. Chemical shifts are expressed in parts per million (ppm) and coupling constants ( $\mathrm{J}$ ) in hertz. Mass spectra were obtained on a Nermag R-10-10C spectrometer with chemical ionization $\left(\mathrm{NH}_{3}\right)$ and mode m/z (amu) [\% relative base peak (100\%)]. Semi-preparative HPLC was performed on a Waters Autopurification ZQ System equipped a 2767 Sample Manager, a 2525 Binary Gradient Module and a 2996 Photodiode Array Detector, coupled to Waters Micromass ZQ analyzer. The HPLC purifications were performed on XTerra Prep RP C18 (19 x 150) columns, using reverse-phase conditions (2 to $100 \%$ acetonitrile with $0.1 \%$ TFA over 20 $\min )$.

\section{Chemical Syntheses}

5-[(6-aminohexyl)carbamoyl]benzene-1,2,3-triyl triacetate (3). Few drops of DMF were added to acetoxygallic acid (1 g, $3.4 \mathrm{mmol}, 1$ equiv) in dry DCM (6 mL). The solution was cooled to $0{ }^{\circ} \mathrm{C}$ and oxalyl chloride $(0.31 \mathrm{~mL}, 3.7 \mathrm{mmol}, 1.5$ equiv) was added dropwise. After 15 min the reaction mixture was allowed to reach room temperature and was stirred for $1 \mathrm{~h}$. The reaction mixture was concentrated under reduced pressure and the residue was resuspended in dry DCM (4.5 mL). A solution containing N-Boc-1,6-hexadiamine (0.72 g, $3.4 \mathrm{mmol}, 1$ equiv) and (i-Pr) $)_{2} \mathrm{NEt}(1.73 \mathrm{~mL}, 10.1 \mathrm{mmol}, 3$ equiv) in DCM (4.5 mL) was added dropwise at $0^{\circ} \mathrm{C}$. After $15 \mathrm{~min}$ the reaction mixture was allowed to reach room temperature and was stirred for $1 \mathrm{~h}$. The reaction mixture was concentrated under reduced pressure and purified by flash column chromatography (AcOEt/petroleum ether 1:1). The resulting product was dissolved in $4 \mathrm{M} \mathrm{HCl}$ in dioxane and stirred for $1 \mathrm{~h}$ at room temperature. $\mathrm{HCl}$ was coevaporated three times with diethyl ether to afford a white paste (mass: 400 mg, yield: 30 \% for 2 steps). IR (film): 3265, 2935, 2860, 2225,1770, 1635, 1585, 
1550, 1490, 1435, 1370, 1315, 1180, 1120, 1050, 1010, 975, 890, 870, 820, 760, 730, 700590 $\mathrm{cm}^{-1} .{ }^{1} \mathrm{H}$ NMR (400 MHz, MeOD): $\delta=7.64$ (s, 1H, CH), 3.39 (t, 2H, CH2), 2.92 (t, 1H, CHz), 2.30 (s, 9H, (CH3)3), $1.66\left(\mathrm{~m}, 4 \mathrm{H},\left(\mathrm{CH}_{2}\right)_{2}\right), 1.44\left(\mathrm{~m}, 4 \mathrm{H},\left(\mathrm{CH}_{2}\right) 2\right) .{ }^{13} \mathrm{C}$ NMR (101 MHz, MeOD): $\delta=169.50$ (Cq), 168.35 (Cq), 133.72 (C(aromatic)), 121.00 (C(aromatic)), 40.81 $\left(\mathrm{CH}_{2}\right), 40.63\left(\mathrm{CH}_{2}\right), 30.11\left(\mathrm{CH}_{2}\right), 28.44\left(\mathrm{CH}_{2}\right), 27.32\left(\mathrm{CH}_{2}\right), 26.96\left(\mathrm{CH}_{2}\right), 20.38\left(\mathrm{CH}_{3}\right)$, $19.96\left(\mathrm{CH}_{2}\right)$. MS (ESI): HRMS (ESI): $(\mathrm{m} / \mathrm{z})$ : calcd for $\mathrm{C}_{19} \mathrm{H}_{26} \mathrm{~N}_{2} \mathrm{O}_{7}+\mathrm{H}$ : 395.1818, found: 395.1823. 11,12-didehydro-5,6-dihydrodibenzo[a,e][8]annulen-5-yl(6-\{[(3,4,5-trihydroxy phenyl)carbonyl]amino\}hexyl) carbamate (5). 5-[(6-aminohexyl)carbamoyl]benzene-1,2,3triyl triacetate 3 (75 mg, $0.2 \mathrm{mmol}$, 1 equiv) was dissolved in DMF (18 mL) and carbonic acid, 5,6-dihydro-11,12-didehydro-dibenzo[ $a, e]$ cycloocten-5-yl ester, 4-nitrophenyl ester $\mathbf{4}^{\text {ref }}$ (80 mg, $0.2 \mathrm{mmol}, 1$ equiv) [ref] followed by triethylamine $(0.08 \mathrm{~mL}, 0.6 \mathrm{mmol}, 3$ equiv) were added. The reaction mixture was stirred overnight at room temperature. DMF was removed under reduced pressure and the product was purified by flash column chromatography (AcOEt/petroleum ether 1:1 then 2:1) (mass: $150 \mathrm{mg}$, yield: $46 \%$ ). The resulting product ( $33 \mathrm{mg}, 0.05 \mathrm{mmol}, 1$ equiv) was dissolved in $\mathrm{THF}$ at $0{ }^{\circ} \mathrm{C}$ and a $1 \mathrm{M}$ solution of $\mathrm{LiOH}(0.15 \mathrm{~mL}, 0.15 \mathrm{mmol}, 3$ equiv) was added. The reaction was monitored by MS until total conversion of the starting material. The product was purified by HPLC ((XTerra Prep RP C18, (25x150 mm Waters)) to give compound 5 (mass: 10 mg, yield: 38 \%). IR (film): 3275, 2935, 1695, 2595, 1515, 1450, 1330, 1200, 1135, 1035, 865, 755, 720, 645, $585 \mathrm{~cm}^{-1}{ }^{1}{ }^{1} \mathrm{H}$ NMR (400 MHz, MeOD): $\delta=7.38$ (d, 1H, aromatic, CH), 7.37-7.29 (m, 7H, aromatics, $\left.(\mathrm{CH})_{7}\right), 6.82$ (s, 2H, $\left.(\mathrm{CH})_{2}\right), 5.42\left(\mathrm{~m}, 1 \mathrm{H}, \mathrm{C}\left(1^{\prime}\right) \mathbf{H}\right), 3.22\left(\mathrm{dd}, 1 \mathrm{H},{ }^{2} J=15.0{ }^{3} \mathrm{~J}=2.0\right.$ $\left.\mathrm{Hz}\left(\mathrm{CH}_{2}\right)\right), 3.11\left(\mathrm{t}, 2 \mathrm{H},{ }^{2} \mathrm{~J}=2.0 \mathrm{~Hz}\left(\mathrm{CH}_{2}\right)\right), 2.82\left(\mathrm{dd}, 1 \mathrm{H},{ }^{2} J=15.0{ }^{3} J=3.8 \mathrm{~Hz}\left(\mathrm{CH}_{2}\right)\right), 1.60-$ 1.29 (m, 10H, $\left(\mathrm{CH}_{2}\right)$ ) $) .{ }^{13} \mathrm{C}$ NMR (100 MHz, MeOD): $\delta=169.12$ (Cq), 156.64 (Cq), 152.34 (Cq), 151.03 (Cq), 136.52 (Cq), 129.57 (C(aromatic)), 127.92 (C(aromatic)), 127.81 (C(aromatic)), 126.89 (C(aromatic)), 126.84 (C(aromatic)), 125.74 (C(aromatic)), 125.48 
(C(aromatic)), 124.99 (C(aromatic)), 123.47 (C(aromatic)), 112.39 (Cq), 109.57 (Cq), 76.40

(CH), $45.74\left(\mathrm{CH}_{2}\right), 40.28\left(\mathrm{CH}_{2}\right), 39.36\left(\mathrm{CH}_{2}\right), 29.40\left(\mathrm{CH}_{2}\right), 29.10\left(\mathrm{CH}_{2}\right), 26.25\left(\mathrm{CH}_{2}\right), 26.06$

$\left(\mathrm{CH}_{2}\right)$.MS (ESI): HRMS (ESI): (m/z): calcd for $\mathrm{C}_{30} \mathrm{H}_{30} \mathrm{~N}_{2} \mathrm{O}_{6}+\mathrm{H}$ : 515.2182, found: 515.2180. $[\alpha]_{\mathrm{D}}^{25}=0.1\left(c=0.004, \mathrm{CH}_{2} \mathrm{Cl}_{2}\right)$.

\section{Chemical coating of the scaffold discs}

Disks $(\mathrm{d}=2.5 \mathrm{~cm}, \mathrm{~h}=0.5 \mathrm{~cm})$ of aluminium oxide scaffolds were incubated in an aqueous solution of compound 5 at increasing concentrations $(0,5$ and $10 \mu \mathrm{M})$ for $24 \mathrm{~h}$ at room temperature in the dark under slight stirring. The disks were washed three times with water and dried under vacuum for $24 \mathrm{~h}$.

\section{Cell assays}

\section{Cell cultures and treatments}

Human SaOs and $\mathrm{U}_{2}$ Os osteosarcoma cells were obtained from the American Tissue Culture Collection (ATCC, Manassas, VA, USA). Human fetal osteoblasts were derived by the explant technique from the femoral bone of a 12-week old fetus according to a protocol accepted by the Lausanne Hospital and University Ethics Committee and with the mother's oral and written approval (protocol No 51/01, 2008). These cells were used at passage 6. Cells were routinely grown in DMEM medium containing $4.5 \mathrm{~g} / \mathrm{L}$ glucose, $10 \%$ fetal calf serum (FCS) and antibiotics (all from Gibco, Basel, Switzerland). On the day of the experiments, cells were detached for the flasks using trypsin-EDTA (Gibco), washed once in complete culture medium and suspended in complete culture medium. Then, 50-75 $\mu \mathrm{L}\left(\sim 500 \times 10^{3}\right.$ cells/scaffold) of the cell suspension were slowly added on the top centre of the scaffold discs (1 cm diameter) inserted into a well of a 24-well culture plate (Costar, Corning Inc, NY, USA) until the red cell suspension was completely absorbed by the scaffolds. Then, $2 \times 100 \mu \mathrm{L}$ of complete culture medium was added. After 6 hours, $200 \mu$ l of complete culture medium 
were added on the bottom of the culture well. Estimation of cell behavior in the scaffolds was determined at different times post seeding (see below).

\section{Evaluation of cell repartition in the scaffold compartments}

The quantification of cell repartition in the 3 compartments of the culture system, i.e. the scaffold, the bottom of the cell culture well under the scaffold and the cells and/or fragments from dead cells in the culture medium, was performed by adapting a previously published radioactive-labeling procedure for cell-cell adhesion ${ }^{20}$ to the scaffold system. Briefly, cell DNA was stably pre-labeled for 24-144 h (depending on the rate of cell proliferation) by tritiated thymidine $\left(0.5 \mu \mathrm{Ci} / \mathrm{mL} \quad\left[{ }^{3} \mathrm{H}\right]\right.$-thymidine, Amersham Pharmacia, Dübendorf, Switzerland), then added to the scaffolds as described above. At the end of the incubation of cells in the scaffolds, $25 \mu \mathrm{L}$ of the culture medium of the cell-scaffolds was removed and dissolved in $0.5 \mathrm{~mL} 1 \%$ SDS-0.1 M NaOH. To quantify cell-associated radioactivity repartition in the foam system, cell-scaffolds were removed from their wells, washed twice in $0.9 \% \mathrm{NaCl}$, and then immersed for $2 \mathrm{~h}$ in $0.5 \mathrm{~mL}$ SDS-NaOH. The cell layers at the bottom of the wells were treated in the same manner. Five $\mathrm{mL}$ of scintillation cocktail (Optiphase Hisafe 3, Perkin-Elmer, Shelton, CT, USA) were added to all samples and radioactivity was quantified in a beta-counter (WinSpectra, Wallac, Germany). Means \pm standard deviation (sd) were calculated.

\section{Evaluation of cell survival and metabolic activity in scaffolds using the MTT assay}

To quantify metabolically active cells in the scaffolds, MTT reduction assay for in scaffold end-point determinations was used. Briefly, scaffolds loaded with cells were exposed to 0.25 mg/mL (final concentration) MTT ((3,4,5-dimethylthiazol-yl)-2,5-diphenyl tetrazolium, Sigma, Buchs, Switzerland) added to complete culture medium for $1 \mathrm{~h}$ (osteosarcoma cells) or 
$4 \mathrm{~h}$ (human fetal osteoblasts) and the blue-violet precipitated formazan in the scaffolds was fixed in 4\% buffered paraformaldehyde and photographed. Alternatively, MTT reduction was quantified according to a modification of a previously described procedure. ${ }^{21}$ Following exposure to MTT for $2 \mathrm{~h}$, the scaffolds were washed twice in PBS and immersed in $0.1 \mathrm{~N} \mathrm{HCl}$ in isopropanol to dissolve the blue precipitated formazan and the extracts were quantified in a multiwell-plate reader (iEMS, Labsystems) at $540 \mathrm{~nm}$.

\section{Evaluation of cell proliferation in the scaffolds using Alamar Blue}

To quantify osteosarcoma cell proliferation in the scaffolds, the Alamar Blue reduction test was used. This assay allows repeated determination of cell metabolic activity in the same sample, providing a cell proliferation time-course. One day after seeding, at day 1 after seeding the scaffolds containing the cells were transferred to a new well containing $0.5 \mathrm{~mL}$ of fresh complete culture medium, then $40 \mu \mathrm{L}$ Alamar Blue (Serotec, Düsseldorf, Germany) were added and the fluorescence was measured in $100 \mu \mathrm{L}$ aliquots removed at 0 min and 45 min after the addition of the Alamar Blue in a multiwell-plate fluorescence reader (Cytofluor, PerSeptive BioSystems) at $\lambda_{e x} / \lambda_{e m}=530 \mathrm{~nm} / 580 \mathrm{~nm}$, respectively. Then the cell-scaffolds were transferred in fresh complete culture medium to continue the incubation for another day, and the process was repeated at day 2 and at day 3. Experiments were repeated at least twice.

Evaluation of long-term survival and proliferation of fetal osteoblasts in the scaffolds using the WST-1 assay

For long-term cultures (6 weeks) of fetal osteoblasts a repeated WST-1 (2-(4-iodophenyl)-3(4-nitrophenyl)-5-(2,4-disulphophenyl)-2H-tetrazolium, Roche Diagnostics, Rotkreuz, Switzerland) assay was performed at 2 week intervals. In a 24-well plate, fetal osteoblasts were seeded on S3 scaffolds ( 500x $10^{3}$ cells/scaffold) and leave to adhere and grow in 
complete culture medium as above. The culture medium of all cell-scaffolds was changed once a week to fresh complete medium. At 2 week intervals, the culture medium of 2-3 scaffolds was removed, $500 \mu \mathrm{L}$ of fresh complete medium containing $50 \mu \mathrm{L}$ WST-1 added and the scaffolds returned to the cell culture incubator. After 5, 30, 60 and $120 \mathrm{~min}, 100 \mu \mathrm{L}$ of WST-1-culture medium were removed and added to a well of a sterile 96-well plate. Optical density of the supernatants was measured at $450 \mathrm{~nm}$ in a multiwell-plate reader (iEMS Reader MF) and the medium was returned to their respective wells and culture continued until the next time-point. At the end of the measurements the metabolic activity of cells in the scaffolds was controlled using a in-scaffold MTT test.

Scanning electron microscopy (SEM) of cells inside the scaffolds

Cells were seeded onto the scaffolds as described above and incubated for 24 h to 6 weeks in complete culture medium. Scaffolds containing the cells were then washed twice in PBS and fixed in $2 \mathrm{~mL}$ of $4 \%$ buffered paraformaldehyde. The scaffold disks were broken in half and their cross section analyzed by means of SEM (LEO 1530, Zeiss Oberkochen). To visualize the cells, mixed mode detection (combining the SE2 and Inlens signal) was used at an acceleration voltage of $3 \mathrm{kV}$.

\section{Osteogenic cell differentiation}

Human $\mathrm{U}_{2} \mathrm{Os}$ cells, SaOs cells or fetal osteoblasts were grown in differentiating medium (adapted from ref. 22), consisting in complete culture medium supplemented with dexamethasone (10 nM final concentration, Sigma-Aldrich), 2-phosphate-ascorbic acid (0.15 $\mathrm{mM}$ final concentration, Sigma-Aldrich) and $\beta$-glycerophosphate (0.25 mM or $2.5 \mathrm{mM}$, final concentration, Sigma-Aldrich) for 7 or 14 days. Medium was changed once a week to complete differentiating medium, then the cell layer was washed and either extracted in RIPA 
buffer for western blotting experiments or in 15 mM Tris pH 8.8 - 0.1\% Triton X-100 (Fluka, Sigma-Aldrich) for $10 \mathrm{~min}$ at $4^{\circ} \mathrm{C}$ for alkaline phosphatase activity determination. Protein content of the extracts was quantified using the BCA kit (BCA Protein Assay Kit, Pierce, Rockford, USA) and bovine serum albumin as standard.

To determine alkaline phosphatase activity (adapted from ref. 23), 10-200 $\mu \mathrm{L}$ of cells extracts adjusted to $200 \mu \mathrm{L}$ with $15 \mathrm{mM}$ Tris $\mathrm{pH} 8.8$ were added in wells of a 96-well plate, then 10 $\mu \mathrm{L}$ of para-nitrophenyl phosphate (pNp, stock solution $1 \mathrm{mg} / \mathrm{mL} \mathrm{H}_{2} \mathrm{O}$, Sigma-Aldrich) were added, and the increase in absorbance at $405 \mathrm{~nm}$ was recorded for $30 \mathrm{~min}$ at $37{ }^{\circ} \mathrm{C}$ in a multiwell plate reader (iEMS, Labsystems). Enzymatic activity was expressed as units of enzymatic activities [1U $=1 \mu$ mole $\mathrm{pNp}$ produced/min, using an $\varepsilon=1.810^{4} \mathrm{M}^{-1} \mathrm{~cm}^{-1}$ for pnitrophenol]. U/mg proteins were calculated and the enzymatic activities of differentiated cells were compared to the enzymatic activities of undifferentiated cells.

For determination of collagen type I by western blotting, cells were grown in $9 \mathrm{~cm}$ diameter Petri dishes, then the cell layers were washed with cold PBS and lysed in $200 \mu \mathrm{L}$ of lysis buffer (150 mM NaCl, 2 mM EDTA, 0.5\% Triton X-100, 50 mM Tris-HCl, 2 mM vanadate, $50 \mathrm{mM} \mathrm{NaF}, \mathrm{pH}$ 7.2) and $10 \mu \mathrm{L}$ of proteinase inhibitor cocktail (Sigma-Aldrich), scraped with a cell scrapper, extracted by 4 cycles of freeze/thawing and centrifuged at $10000 \mathrm{rpm}$ (10 000g) at $4{ }^{\circ} \mathrm{C}$ for $10 \mathrm{~min}$. Protein content in the supernatants was quantified using the BCA reagent and an extract volume corresponding to $30 \mu \mathrm{g}$ proteins was heated for $5 \mathrm{~min}$ at $95{ }^{\circ} \mathrm{C}$ in the absence of a reducing agent, submitted to SDS-PAGE and transferred onto a nitrocellulose membrane (Whatman, Dassel, Germany). The membranes were blocked with 5\% fat-free milk in PBS, washed in 0.05\% Tween-20 (Sigma-Aldrich) in PBS and incubated overnight at $4{ }^{\circ} \mathrm{C}$ with a polyclonal anti-human collagen type I pro 2 chain antibody (Abcam, Cambridge, UK; anti-Col1A2, ab96723; diluted 1:2500 in 1\% fat-free milk and $0.05 \%$ Tween-20 in PBS) then exposed for 60 min to peroxidase-conjugated anti-rabbit antibody 
(Promega, diluted 1:5000) and visualized using chemiluminescence (ECL, GE Healthcare, Amersham, UK). To control for loading, the membranes were stripped by successive incubation in 0.1 M glycine pH 2.3, $1 \mathrm{M} \mathrm{NaCl}$ in PBS and 0.05\% Tween-20 in PBS, blocked for $1 \mathrm{~h}$ with 5\% fat-free milk in PBS and exposed to a monoclonal anti-human $\alpha$-tubulin antibody (Abcam, diluted 1:10000) for $1 \mathrm{~h}$, then to a peroxidase-conjugated anti-mouse antibody (Sigma-Aldrich, diluted 1:5000) at rt and treated as above. For the purpose of comparison human skin fibroblasts ${ }^{24}$ were treated under the same conditions.

\section{Click-reaction on the biomaterial}

L-azidohomoalanine (AHA) was purchased from Invitrogen, bovine serum albumin (BSA), from Sigma-Aldrich, Buchs, Switzerland. Nine-cm Petri dishes (Costar) were coated with $1000 \mu \mathrm{g} / \mathrm{mL}$ Rat Tail collagen I (Invitrogen) according to the supplier's protocol and human fetal osteoblasts were then grown in the dishes for $24 \mathrm{~h}$ until the cells are $80-90 \%$ confluent. The cells were washed with PBS and incubated in methionine-free DMEM culture medium (Gibco) for 60 min to deplete methionine reserves. Then the cells were incubated overnight in the presence of AHA (50 $\mu \mathrm{M}$ final concentration) in fresh complete methionine-free culture medium. The culture medium was removed and the cell layers were washed twice with PBS. Collagen coating was degraded by adding $0.1 \mathrm{mg} / \mathrm{mL}$ collagenase (Sigma-Aldrich) in PBS at $37^{\circ} \mathrm{C}$ for $45 \mathrm{~min}$. The osteoblasts were then counted. Three $\mathrm{mL}$ of the cell suspension $\left(10^{5}\right.$ cells/mL) were added on unfunctionalized or functionalized scaffolds with compound 5 , in a 6-well plate (Costar) and incubated for $1 \mathrm{~h}$ at rt under slight agitation. The disks were washed once with PBS, fixed in cold methanol $\left(-20^{\circ} \mathrm{C}\right)$ for $5 \mathrm{~min}$ and incubated in $5 \%$ BSA for $1 \mathrm{~h}$ at rt. Cells were stained for 5 min at rt with a solution containing $0.05 \%$ crystal violet (SigmaAldrich) and $1.5 \%$ glacial acetic acid in water. Cells were imaged by stereomicroscopy (MZ16 FA Leica/DFC 480 Leica, $0.63 \mathrm{X}$ and $1.6 \mathrm{X}$, zoom $72 \mathrm{X}$ ), 3 pictures for each 
treatment were taken and the cell number was evaluated using the Image $\mathrm{J}$ software. 


\section{Results}

Preparation and characterization of the scaffolds

We have previously designed techniques to prepare porous ceramics via a direct foaming method. ${ }^{13-17}$ The adaption of this foaming method allowed the production of macroporous scaffolds which are tailorable not only in pore size, but also in pore interconnectivity. ${ }^{18,19}$ In the present study, we made use of this direct foaming method to produce scaffolds from calcium aluminate and evaluated them as potential permanent bone graft materials. To obtain porous scaffolds with different microstructures, ceramic foams with varying pore sizes and porosities were produced from slightly varying compositions (Table 1). The sintered specimens could easily be machined into different shapes (Figure 1a) and the SEM micrographs showed an open porosity, resulting in a network of interconnected pores (Figure 1b-d). Size distributions of the scaffolds pores and pore-openings were determined (Figure 2). As shown in Table 1 and Figure 2, scaffolds S1 and S2 are equal in average pore diameter $(170 \mu \mathrm{m})$ and display pore openings (or windows) of similar sizes (50 $\mu \mathrm{m}$ and $60 \mu \mathrm{m}$ in diameter, respectively). The microstructure of scaffold S3 has a two to three times larger average pore size of $460 \mu \mathrm{m}$ and pore openings of $95 \mu \mathrm{m}$. The porosity (or air content) of the different scaffolds is the same for scaffolds S1 and S2 (76 vol\%) and is higher for scaffold S3 (86 vol\%). Thus by varying the suspension composition, foam scaffolds with different microstructures and porosities were obtained.

\section{Interaction of human osteosarcoma cells with the scaffolds}

$\mathrm{U}_{2} \mathrm{Os}$ and SaOs human osteosarcoma cells are widely used as cell models for human bonederived cells and are more easily available than primary human bone cells. Thus, in order to select the scaffolds with optimal characteristics allowing human bone cells to adhere, survive and migrate, these cells were used as initial screening tools. To evaluate the biocompatibility 
of the scaffold materials, the metabolic activity of human $\mathrm{U}_{2} \mathrm{O}_{\mathrm{s}}$ osteosarcoma cells 1 to 3 days after seeding in the 3 scaffolds was determined using the Alamar Blue assay, which allows repeated evaluation of the same samples (Figure 3). Cells were seeded in the scaffolds by placing complete cell culture medium containing phenol red and cells onto the top of the scaffolds. After the absorption of the cell culture medium in the scaffolds, the red cell culture medium slightly drained from below the three scaffolds, indicating that the microstructures of the scaffolds were permissive for the flowthrough of cell culture medium. Under an inverted optical microscope after 1 day culture, few cells were seen adhered on the bottom of the culture wells under scaffolds S1 and S2, while more cells were found on the bottom of the wells under scaffold S3. Thus, the initial trans-scaffold migration of the cells, as expected, was mainly determined by the pore size and the size of the inter-pore openings of the scaffolds. The cells which migrated outside the 3 scaffolds were well spread and attached to the well plate bottoms, were metabolically active as demonstrated using a MTT test (not shown), suggesting that the cell viability was not affected by the scaffold material during initial cell migration across the scaffolds.

In order to determine the repartition of cells and cell components in the 3 compartments of the scaffold culture system, i.e. the cells in the scaffolds, the cells on the bottom of the cell culture wells under the scaffold, and the culture medium bathing the scaffolds, the DNA of $\mathrm{U}_{2} \mathrm{Os}$ and SaOs human osteosarcoma cells was stably pre-labeled with radioactive $\left[{ }^{3} \mathrm{H}\right]$-thymidine and the radioactivity was quantified in the different partitions of the cell-scaffold systems (Supplementary Information, Table S1). For all cell-scaffolds, the amount of radioactivity measured in the scaffolds was always much higher than in the well plate bottoms or in the culture media, for all time periods and both cell lines, strongly suggesting that most cells were retained inside the scaffolds. Thus, ceramic calcium aluminate scaffolds are good substrates for long-term adhesion and survival of human bone-derived cells. 
The aspect of human SaOs and $\mathrm{U}_{2} \mathrm{Os}$ osteosarcoma cells grown for either 1 day or 4 days in the three different scaffolds was examined using SEM (Figure 4A). The micrographs showed that the cells adhered to and spread onto the ceramic surface of all 3 scaffolds, indicating a good acceptance of the scaffold material by the living cells. To determine if the cells were able to migrate across the whole scaffold, $\mathrm{U}_{2} \mathrm{Os}$ cells were seeded on the top of scaffold $\mathrm{S} 3$ (Figure 4B, arrow) and grown for 4 days in the scaffolds, then after fixation in buffered paraformaldehyde, the scaffold was broken in the middle and the whole fracture section examined by SEM (Figure 4B, left panel), showing cells located at different levels of the scaffold from the initial seeding point at the top of the scaffold. The cells were examined at higher magnification (Figure 4B, panels 1 to 5) showing well spread cells on their substrate at all levels of localization in the scaffolds. Thus, the SEM images and the proliferation experiments strongly suggested biocompatibility of the different scaffold materials and permissiveness for living cell migration across the scaffolds. In particular scaffold S3 presented with optimal properties for cell migration, and was selected for further evaluation using human primary fetal osteoblasts.

Interaction of human fetal osteoblasts with the scaffold S3

Human primary fetal osteoblasts derived from the femoral bone of a 12 -week old fetus ${ }^{25,26}$ were first compared to human osteosarcoma cells for their expression of differentiation markers of bone cells, either under standard culture conditions or in differentiating cell culture medium. Three markers of the human osteoblast cell lineage were analyzed: the expression of the proa2 chain of type I collagen (Figure 5A), alkaline phosphatase activity (Figure 5B) and the cell ability to deposit calcium (Figure 5C). Collagen type I is found in most connective tissues and defects of this protein have been involved in disorders of the bone, such as osteogenesis imperfecta. Human skin fibroblasts were used as positive controls of the 
expression of collagen type I. Human fetal osteoblasts and skin fibroblasts expressed collagen type I, but not the two human osteosarcoma cells lines. This expression could not be induced when the osteosarcoma cells were grown in differentiating medium for 7 to 14 days, and no further increase in collagen I expression by fetal osteoblasts grown in differentiating medium for up to 14 days was observed (results not shown). Alkaline phosphatase activity was increased over basal activity level by a factor 2 in the two human osteosarcoma cells and by a factor 20 in the fetal osteoblasts by culturing them for up to 14 days in differentiating medium. It must be underlined that the basal alkaline phosphatase activity of SaOs cells is much higher than that of the two other cell lines. Human fetal osteoblasts were able to deposit calcium. Therefore these human bone-derived histocompatible fetal cells represent human bone-derived cells able to differentiate into bone cells, and are relevant models to evaluate the interaction of human primary bone-derived cells with the newly prepared S3 scaffolds.

The radioactivity of human fetal osteoblasts stably pre-labeled with radioactive $\left[{ }^{3} \mathrm{H}\right]-$ thymidine was quantified in the cells in the S3 scaffold, in the cells on the bottom of the cell culture wells under the scaffold, and in the culture medium bathing the scaffolds 2 days and 6 days after seeding (Figure 6A). As for human osteosarcoma cells, the amount of radioactivity measured in the scaffolds was much higher than in the two other compartments of the system, but some cells could be detected on the bottom of the culture wells, under the scaffold. Six days after seeding in scaffold S3, the fetal osteoblasts were examined using SEM (Figure 6B). The micrographs showed that the cells adhered to and spread onto the ceramic surface of the scaffolds, able to make cell bridges across the pores in the image which we selected as an example. Then, the long-term proliferation of human fetal osteoblasts in the scaffolds was evaluated using a WST-1 assay demonstrating that the cells proliferated in the scaffolds for up to 6 weeks (Figure 6C). The proliferative properties of human fetal osteoblasts were maintained for cells seeded in the scaffold S3 in differentiating medium and were comparable 
to the proliferation of cells grown in the same medium on cell culture plastic (results not shown). To confirm the long-term in-scaffold viability and metabolic activity of fetal osteoblasts after culture inside the scaffolds, the human fetal osteoblasts were grown for 6 weeks in scaffolds S3, or scaffold S1 for the purpose of comparison (Figure 6D). Then a modified in-scaffold MTT assay (which is based upon the reduction of the soluble yellow MTT molecules to a violet formazan precipitate by the respiratory chain of living cell mitochondria), was developed. The cell-associated violet precipitate proved cell metabolic activity and viability inside the scaffold S3 for long period of time (Figure 6D). The violet cell staining on both the top and bottom sides of scaffold S3 suggested that viable cells still colonized the whole scaffold after 6 weeks, whereas for scaffolds S1, only the up side, where the cells were initially seeded, but not the down side of the scaffolds was stained. Thus a large-porous microstructure facilitates primary human fetal osteoblasts migration across the scaffolds and allows their survival in the scaffolds for at least 6 weeks.

In order to further determine the repartition of primary human fetal osteoblasts in the scaffolds S3 6 weeks after seeding, the scaffolds were fixed in buffered paraformaldehyde, broken in the middle and the whole fracture section examined by SEM. Low magnification (Figure 7a) was used to visualize showing cells located at different levels of the scaffold (highlighted by white circles and numbers) from the initial seeding at the top of the scaffold. Then, the cells were examined at higher magnification (Figure 7b, panels 1 to 9), showing well spread and viable cells at all levels of localization in the scaffolds.

Therefore the porous calcium aluminate ceramic scaffolds that we developed, in particular scaffold S3, and evaluated displayed the requested characteristics that we initially defined: permissiveness for human bone cells trans-scaffold migration and in-scaffold survival and proliferation. However, we observed that the addition of human bone-derived cells, either osteosarcoma cells or fetal osteoblasts, on the top side of the scaffolds S3 resulted in the rapid 
appearance of a few cells on the bottom side of the scaffolds, suggesting that their adhesion was not rapid enough to ensure the optimal cellularization of these scaffolds with bone cells and should be improved

\section{Click-functionalization of the scaffolds and adhesion of human fetal osteoblasts}

We have previously shown that alumina-based scaffolds can be chemically functionalized with gallate-based ligands. ${ }^{27}$ We have also previously shown that human fetal osteoblasts can be chemically functionalized using biocompatible click chemistry. ${ }^{28}$ Thus, in order to enhance the adhesion of the fetal osteoblasts to the scaffold, we combined these two approaches by designing and synthesizing (Scheme 1) compound 5, an hetero-bifunctional ligand bearing a gallate functionality and an activated alkyne. The alumina scaffolds were functionalized with compound 5, then the azido-modified human fetal osteoblasts $\left(10^{6}\right.$ cells per scaffold) were added to scaffolds which were either unfunctionalized or had been pre-functionalized with compound 5 (5 or $10 \mu \mathrm{M}$ ). After the washing and fixation steps, the cells were stained with crystal violet (Figure 8A). Cell adhesion to the scaffolds was imaged with a stereomicroscope and the number of adhered cells was quantified by the Image $\mathrm{J}$ software (Figure $\mathbf{8 B}$ ). Quantification of the number of adhered cells showed that the functionalization of the scaffolds with compound $\mathbf{5}$ increased the number of adhered cells, with a very strong dependency on the amount of compound $5(\mathrm{r}=1.00,10 \mu \mathrm{M} v s 5 \mu \mathrm{M})$ used for the functionalization of the scaffolds. The observed increase of the number of adhered cells was statistically significant $(\mathrm{p}<0.001)$. 


\section{Discussion}

Major challenges in the development of permanent bone substitutes are biocompatibility and permissiveness of the implant for the migration across its whole structure of bone and boneassociated cells to ultimately allow the development of adequate bone-mimicking tissue and improve integration of the implant in the tissue. Many previous studies have addressed the development of biodegradable materials for small bone defects, whereas studies of 3dimensional scaffolds able to support the survival of bone-derived cells for permanent replacement of bone defects are scarcer. These permanent scaffolds should be able to reproduce the structure of the bone matrix, and to be modeled in shapes and characteristics similar to the bone tissue to be replaced, while maintaining their structural stability. The ability of such scaffolds to form a porous interconnected network spanning the entire structure is also requested in order for relevant cells to develop into a functional bone tissue. Ceramicsbased materials fulfill many such requirements and are osteoconductive and biocompatible. However, few ceramics with controlled pores spanning the scaffold structures and allowing the migration and adhesion of cells across the whole structure, have presently been described. Most described methods to produce porous scaffolds use organic materials and their subsequent elimination from the structure during the sintering process. Previous work by others has shown that titanium-based metal implants of the second generation can be made more porous to allow bone growth through the implant. ${ }^{29,30}$ Titanium-based foams are made by impregnating polyurethane forms with titanium powder, hardening of the structure and washing away of the polyurethane, resulting in a material with lower stiffness than solid titanium and which is less brittle than ceramic materials. The materials performed well as permanent implants for disc replacement in animal models. ${ }^{31-33}$ Ceramics derived from calcium phosphate mimics the mineral structure of bone, and bone cells were shown to recognize and bind to such ceramics. ${ }^{34,35}$ Calcium phosphate-based ceramics have been 
previously shown to display bone integration properties ${ }^{36,37}$ and calcium aluminate further increases osteointegration. ${ }^{38,39}$ Alumina ceramics, including porous alumina allows the attachment, growth and differentiation of bone cells, the materials grain microstructure being important for cell behavior, including for a human bone-derived cell line..$^{5-7}$ The surface reactivity of bioactive glass ceramics and the sintering process were shown to affect interaction with human osteoblasts, and ultimately their bone integration potential. ${ }^{40}$

In order to develop a permanent bone replacement, which displays an open-porous microstructure allowing the establishment of a continuous cellular network of bone-derived cells, we developed a different methodology based on calcium aluminate scaffolds produced from a recently modified direct foaming method. ${ }^{13-19,41}$ In order to meet the needs and challenges of open-pores microstructures required, the so-called limited coalescence phenomenon was exploited, where bubbles start to disproportion and coalesce instantly after foaming, until a new equilibrium is reached. ${ }^{12-17}$ Then, upon bubble growth, the foam lamellae start to thin, layer by layer, until the bubble eventually ruptures. This second phenomenon, which is called partial coalescence, can occur during the limited coalescence step, especially if the inter-particle forces are attractive. The freezing of this transitory state of partial coalescence will then lead to an open-porous microstructure. For the present study, foams made from alumina particles were combined with a calcium aluminate cement reaction. ${ }^{18,19}$ Upon setting and sintering, open-porous scaffolds with different microstructures, which can be machined into the desired shapes, were produced, characterized and engineered with human bone-derived cells. In the present feasibility study, we investigated three scaffolds with various pores and pore openings for biocompatibility and the adhesion behavior, the inscaffold viability and the metabolic activity of human bone-derived cells, using first human osteosarcoma cells to select the scaffolds with optimal porosities, then primary human fetal osteoblasts ${ }^{25,26}$ as potential histocompatible cells ${ }^{9}$ for cell-engineering the scaffolds prior to 
their implantation into patient receivers. These studies demonstrated the biocompatibility of the three scaffolds for human bone-derived cells whatever their fine chemical and physical characteristics, and importantly also demonstrated that the scaffold porosities determined the potential of cells to migrate across the entire scaffolds and form functional cellular networks across the entire structure. Therefore these experiments allowed defining a minimal pore opening limit around $100 \mu \mathrm{m}$ in order to allow cell passage and whole structure colonization. Following this passage, cells were still alive after long-term culture, and cells inside the scaffolds demonstrated a steady potential for proliferation without any sign of cytotoxicity. The SEM observations showing cells throughout the entire scaffold proved that open channels span throughout the whole scaffold structures and that the material is permissive for human cell migration and proliferation. SEM also confirmed that the cells adhered to and were well spread onto the ceramic surface, again indicating a good acceptance and biocompatibility of the scaffold materials by living human primary fetal cells and provided a proof of concept for their potential as permanent implants for bone tissue engineering.

However, the adhesion of human bone-derived cells onto the large pore scaffolds was not rapid enough to ensure the optimal cellularization of these scaffolds. Combining our previous observations that alumina-based scaffolds can be chemically functionalized with gallate-based ligands, ${ }^{27}$ and that human fetal osteoblasts can be chemically functionalized using biocompatible click chemistry, ${ }^{28}$ we showed here that the number of human fetal osteoblasts adhering to the scaffolds can be enhanced by their covalent binding to the scaffolds using an hetero-bifunctional ligand and biocompatible click-chemistry. Therefore, we show here that large-pore alumina-based scaffolds and primary human fetal cells derived from the fetal bones are an interesting potential source of bone precursor cells to prepare permanent cellularized bone implants for tissue engineering, using chemical functionalization of the scaffolds. This acceptance of the developed scaffolds by such cells is encouraging for further development 
toward bone tissue engineering.

\section{Acknowledgements}

We thank Mr. P. Elser and Mrs. C Chappuis-Bernasconi for excellent technical assistance. This work was supported by the Swiss National Research Foundation (grants $n^{\circ}$ CR23I3124753 and CR22I2-140866), the Sandoz Family Foundation and Foundation S.A.N.T.E.

Contribution of the authors: FKJ designed, prepared, characterized the scaffolds, participated to the cell experiments and to the writing of the manuscript; CS and LAA prepared the human fetal osteoblasts; FB designed, performed the covalent functionalization of the scaffolds and participated to the cell experiments; HC and SGL participated in the chemical characterization of the scaffolds; DS participated to the click-chemistry cell experiments; LJG participated to the design of the scaffolds; LJJ designed and participated to the cell experiments and prepared the writing of the manuscript; UTG designed and characterized the scaffolds and participated to the writing of the manuscript.

Supporting Information Available: Table S1: Radioactivity repartition of thymidine-labeled osteosarcoma cells in the three compartments of the cell-scaffold systems: in the scaffolds, on the bottom of the wells and in the culture medium. Detailed chemical syntheses: Synthesis and characterization of compound 5-[(6-aminohexyl)carbamoyl]benzene-1,2,3-triyl triacetate (3); Synthesis and characterization of 11,12-didehydro-5,6-dihydrodibenzo[a,e][8]annulen-5yl(6-\{[(3,4,5-trihydroxy phenyl)carbonyl]amino $\}$ hexyl) carbamate (5). This material is available free of charge via the Internet at http://pubs.acs.org. 
Abbreviations 


\section{References}

1. Bohner, M. (2010) Resorbable biomaterials as bone graft substitutes. Mat. Today 13(1-2), 24-30.

2. Cortet, B. (2011) Bone repair in osteoporotic bone: postmenopausal and cortisone-induced osteoporosis. Osteoporosis Int. 22, 2007-2010.

3. Triplett, R.G., and Schow, S.R. (1996). Autologous bone grafts and endosseous implants: Complementary techniques. J. Oral Maxillofac. Surg. 54, 486-494.

4. Griffith, L.G., and Naughton, G. (2002) Tissue engineering--current challenges and expanding opportunities. Science 295, 1009-1014.

5. Ryan, G., Pandit, A., and Apatsidis, D. P. (2006) Fabrication methods of porous metals for use in orthopaedic applications. Biomaterials 27, 2651-2670.

6. Heinl, P., Muller, L., Korner, C., Singer, R. F., and Muller, F. A. (2008) Cellular Ti-6Al$4 \mathrm{~V}$ structures with interconnected macro porosity for bone implants fabricated by selective electron beam melting. Acta Biomat. 4, 1536-1544.

7. Chanda, A., Singha Roy R., Xue, W., Bose, S., and A. Bandyopadhyay, A. (2009) Bone cell-materials interaction on alumina ceramics with different grain sizes. Mat. Sci. Eng. 29C, 1201-1206.

8. Hohlfeld, J., de Buys Roessingh, A. D., Hirt-Burri, N., Chaubert, P., Gerber, S., Scaletta, C., Hohlfeld, P., and Applegate, L. A. (2005) Tissue engineered fetal skin constructs for paediatric burns. Lancet 366, 840-842.

9. Montjovent, M. O., Bocelli-Tyndall, C., Scaletta, C., Scherberich, A., Mark, S., Martin, I., Applegate, L. A., and D. P. Pioletti, D.P. (2009) In vitro characterization of immune-related properties of human fetal bone cells for potential tissue engineering applications. Tissue Engin. 15A, 1523-1532.

10. Montjovent, M. O., Mathieu, L., Hinz, B., Applegate, L. A., Bourban, P. E., Zambelli, P. Y., Månson, J. A., and D. P. Pioletti, D.P. (2005) Biocompatibility of bioresorbable poly(Llactic acid) composite scaffolds obtained by supercritical gas foaming with human fetal bone cells. Tissue Engin. 11, 1640-1649.

11. Montjovent, M. O., Mark, S., Mathieu, L., Scaletta, C., Scherberich, A., Delabarde, C., Zambelli, P. Y., Bourban, P. E., Applegate, L. A., and D. P. Pioletti, D. P. (2008) Human fetal bone cells associated with ceramic reinforced PLA scaffolds for tissue engineering. Bone 42, 554-564.

12. Ergun, A., Yu, X., Valdevit, A., Ritter, A., and Kalyon, D. M. (2011) In vitro analysis and mechanical properties of twin screw extruded single-layered and coextruded multilayered poly(caprolactone) scaffolds seeded with human fetal osteoblasts for bone tissue engineering. J. Biomed. Mat. Res. 99A, 354-366.

13. Gonzenbach, U. T., Studart, A. R., Tervoort, E., and Gauckler, L. J. (2006) Ultrastable particle-stabilized foams. Angew Chemie-Int Ed, 45, 3526-3530. 
14. Gonzenbach, U. T., Studart, A. R., Tervoort, E., and Gauckler, L. J. (2006) Stabilization of foams with inorganic colloidal particles. Langmuir 22, 10983-10988.

15. Gonzenbach, U. T., Studart, A. R., Steinlin, D., Tervoort, E., and Gauckler, L. J. (2007) Processing of particle-stabilized wet foams into porous ceramics. J. Am. Ceram. Soc. 90, 3407-3414.

16. Gonzenbach, U. T., Studart, A. R., Tervoort, E., and Gauckler, L. J. (2007) Tailoring the microstructure of particle-stabilized wet foams. Langmuir 23. 1025-1032.

17. Gonzenbach, U. T., Studart, A. R., Tervoort, E., and Gauckler, L. J. (2007) Macroporous ceramics from particle-stabilized wet foams. J. Am. Ceram. Soc. 90, 6-22.

18. Krauss Juillerat, F., Gonzenbach, U. T., Studart, A. R., and Gauckler, L J. (2010) Selfsetting particle stabilized foams with hierarchical pore structures. Materials Lett. 2010, 64, 1468-1470.

19. Krauss Juillerat, F., Gonzenbach, U. T., Elser, P., Studart, A. R., and Gauckler, L J. (2011) Microstructural control of self-setting particle-stabilized ceramic foams. J. Am. Ceram. Soc. 94, 184-190.

20. Lohm, S., Peduto-Eberl, L., Lagadec, P., Renggli-Zulliger, N., Dudler, J., Jeannin, J. F., and L. Juillerat-Jeanneret, L. (2005) Evaluation of the interaction between TGF beta and nitric oxide in the mechanisms of progression of colon carcinoma. Clin. Exp. Metastasis 22, 341349.

21. Berger, Y., Greppi, A., Siri, O., Neier, R., and Juillerat-Jeanneret, L. (2000) Ethylene glycol and amino acid derivatives of 5-aminolevulinic acid as new photosensitizing precursors of protoporphyrin IX in cells. J. Med. Chem. 43, 4738-4746.

22. Sottile, V., Halleux, F., Bassilana, F., Keller, H., and Seuwen, K. (2002) Stem cell characteristics of human reabecular bone-derived cells. Bone 5, 699-704.

23. Nifuji, A., Ideno, H., Ohyama, Y., Takanabe, R., Araki, R., Abe, M., Noda, M., and H. Shibuya, H. (2010) Nemo-like kinase (NLK) expression in osteoblastic cells and suppression of osteoblastic differentiation. Exp. Cell Res. 316, 1127-1136.

24. Fiaux, H., Popowycz, F., Favre, S., Schütz, C., Vogel, P., Gerber-Lemaire, S., JuilleratJeanneret, L. (2005) Functionalized pyrrolidines inhibit $\alpha$-mannosidase activity and growth of human glioblastoma and melanoma cells. J. Med. Chem. 48, 4237-4246.

25. Quintin, A., Hirt-Burri, N., Scaletta, C., Schizas, C., Pioletti, D. P., and Applegate, L. A. (2007) Consistency and safety of cell banks for research and clinical use: preliminary analysis of fetal skin banks. Cell Transplant. 16, 675-684.

26. Quintin, A., Schizas, C., Scaletta, C., Jaccoud, S., Chapuis-Bernasconi, C., Gerber, S., Osterheld, M. C., Juillerat, L., Applegate, L. A., and Pioletti, D. P. (2009) Isolation and in vitro chondrogenic potential of human foetal spine cells. J. Cell. Mol. Med. 13, 2559-2569.

27. Comas, H., Laporte, V., Borcard, F., Miéville, P., Krauss Juillerat, F., Caporini, M. A., 
Gonzenbach, U. T, Juillerat-Jeanneret, L., Gerber-Lemaire, S. (2012) Surface functionalisation of alumina ceramic foams with organic ligands. ACS Appl. Mater. Interfaces 4, 573-576.

28. Borcard, F., Chapuis-Bernasconi, C., Comas Blanco, H., Dumont, A. L., Scaletta, C., Applegate, L. A., Krauss Juillerat, F., Gonzenbach, U.T., Gerber-Lemaire, S., JuilleratJeanneret, L. (2011) Covalent cell surface functionalization of human fetal osteoblasts for tissue engineering. Bioconj. Chem. 22, 1422-1432.

29. Imwinkelried, T. (2007) Mechanical properties of open-pore titanium foam. J. Biomed. Mat. Res. 81A, 964-970;

30. Singh, R., Lee, P. D., Lindley, T. C., Kohlhauser, C., Hellmich, C., Bram, M., Imwinkelried, T., and Dashwood, R. J. (2010) Characterization of the deformation behavior of intermediate porosity interconnected $\mathrm{Ti}$ foams using micro-computed tomography and direct finite element modeling. Acta Biomat. 6, 2342-2351.

31. Wazen, R. M., Lefebvre, L. P., Baril, E., and Nanci, A. (2010) Initial evaluation of bone ingrowth into a novel porous titanium coating. J. Biomed. Mat. Res. 94B, 64-71.

32. Willie, B. M., Yang, X., Kelly, N. H., Merkow, J., Gagne, S., Ware, R., Wright, T .M., and M. P. Bostrom, M. P. (2010) Osseointegration into a novel titanium foam implant in the distal femur of a rabbit. J. Biomed. Mat. Res. 92B, 479-488.

33. Willie, B. M., Yang, X., Kelly, N. H., Han, J., Nair, T., Wright, T. M., van der Meulen, M. C., and Bostrom, M. P. (2010) Cancellous bone osseointegration is enhanced by in vivo loading. Tissue Engin. 16C, 1399-1406.

34. Trojani, C., Boukhechba, F., Scimeca, J. C., Vandenbos, F., Michiels J. F., Daculsi, G., Boileau, P., Weiss, P., Carle, G. F., and Rochet, N. (2006) Ectopic bone formation using an injectable biphasic calcium phosphate/Si-HPMC hydrogel composite loaded with undifferentiated bone marrow stromal cells. Biomaterials 27, 3256-3264.

35. Klenke, F. M., Liu, Y. L., Yuan,H. P., Hunziker, E. B., Siebenrock, K. A., and Hofstetter, W. (2008) Impact of pore size on the vascularization and osseointegration of ceramic bone substitutes in vivo. J. Biomed. Mat. Res. 85A, 777-786.

36. Ducheyne, P., and Qiu, Q. (1999) Bioactive ceramics: the effect of surface reactivity on bone formation and bone cell function. Biomaterials 20, 2287-2303.

37. Meijer, G. J., de Bruijn, J. D., Koole,R., and van Bitterswijk, C. A. (2007) Cell-based bone tissue engineering. PloS Med. 4. e9.

38. Axen, N., Engqvist, H., Lööf, J., Thomsen, P., and Hermansson, L. (2004) In vivo hydrating calcium aluminate coatings for anchoring of metal implants in bone. Key Engin. Mat. 254-256, 265-268.

39. Axen, N., Persson, T., Björklund, K., Engqvist, H., and L. Hermansson, L. (2005) An injectable bone void filler cement based on Ca-aluminate. Key Engin. Mat. 284-286, 831-834. 
40. Gough, J. E., Clupper,D. C., and Hench, L. L. (2004) Osteoblast responses to tape-cast and sintered bioactive glass ceramics. J. Biom. Mat. Res. 69A, 621-628.

41. Wong, J. C. H., Tervoort, E., Busato, S., Gonzenbach, U. T., Studart, A. R., Ermanni, P., and Gauckler, L. J. (2009) Designing macroporous polymers from particle-stabilized foams. J. Mat. Chem. 19, 5129-5133.

Ref. Compound 4 was prepared according to the procedure reported in: Ning, X.; Guo, J.; Wolfert, M. A.; Boons, G.-J. (2008) Visualizing Metabolically Labeled Glycoconjugates of Living Cells by Copper-Free and Fast Huisgen Cycloadditions. Angew. Chem. Int. Ed., 47, 2253-2255. Mbua, N. E., Guo, J., Wolfert, M. A., Steet, R., and Boons, G.-J.(2011) Strainpromoted alkyne-azide cycloadditions (SPAAC) reveal new features of glycoconjugate biosynthesis. ChembioChem, 12, 1912-1921. 


\section{Tables}

\begin{tabular}{ccccccc} 
scaffold & average pore & average pore porosity & $\mathrm{Al}_{2} \mathrm{O}_{3}$ & $\mathrm{CA}-270$ & ratio cement \\
No & size $[\mu \mathrm{m}]$ & opening $[\mu \mathrm{m}]$ & {$[\mathrm{vol} \%]$} & {$[\mathrm{wt} \%]$} & {$[\mathrm{wt} \%]$} & to alumina \\
\hline S1 & 170 & 50 & 76 & 12.7 & 33.7 & 2.7 \\
S2 & 170 & 60 & 76 & 32.9 & 4.3 & 0.1 \\
S3 & 460 & 95 & 86 & 10.8 & 26.3 & 2.4 \\
\hline
\end{tabular}

Table 1: Physicochemical characteristics of the different scaffolds. 


\section{Schemes:}

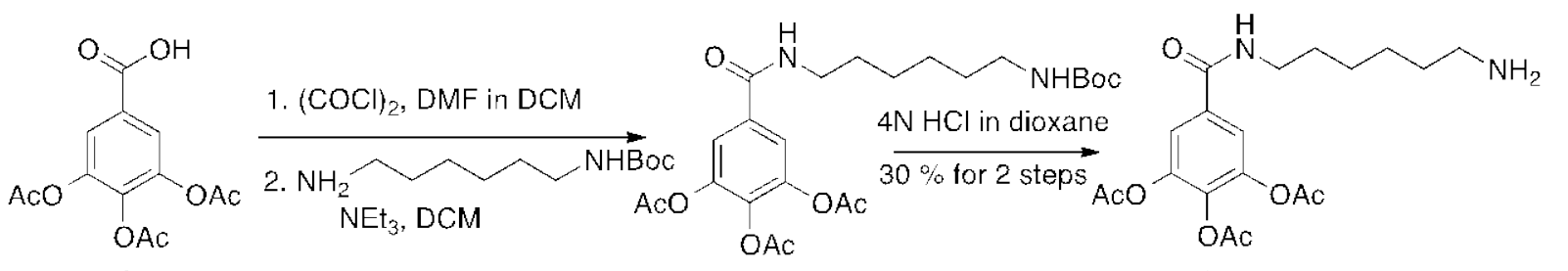

1

2

1. $\mathrm{NEt}_{3}, \mathrm{DMF}$

(1)

$\mathrm{O}=\mathrm{O} \quad 17 \%$ for 2 steps

0

$=\mathrm{NO}_{2}$

2. $\mathrm{LiOH}, \mathrm{THF} / \mathrm{H}_{2} \mathrm{O}$

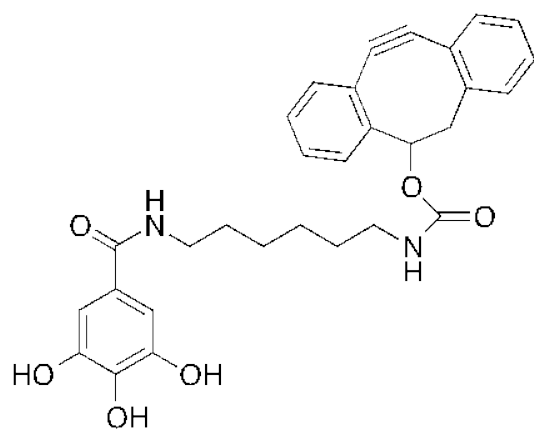

5

Scheme 1: Synthesis of compound 5 for the click-reaction of human fetal osteoblasts on scaffolds.

Acetoxygallic acid $\mathbf{1}$ was first converted into the corresponding acyl chloride by reaction with oxalylchloride in presence of DMF and then coupled to N-Boc-1,6-hexadiamine to afford intermediate 2. After deprotection of the amine under acidic conditions, the-compound 3 reacted with 6-dihydro-11,12-didehydro-dibenzo[ $a, e]$ cycloocten-5-yl ester, 4-nitrophenyl ester 4 in the presence of triethylamine. Finally, deprotection of the three-hydroxyl groups under basic conditions provided the desired compound $\mathbf{5}$ which was further used for the functionalization of the biomaterial and the click reaction with human fetal osteoblasts. 


\section{Figure Legends}

Figure 1: Macroscopic and microscopic aspect of the scaffolds.

Upper panel: a) macrophotographs of the three different scaffold materials (from left to right: scaffold S1, scaffold S2 and two pictures of scaffold S3);

Lower panels: SEM micrographs of b) scaffold S1; c) scaffold S2; d) scaffold S3.

Figure 2: Size distribution of the pores and pore openings for the 3 different scaffolds.

To define the diameters of the pores and pore-openings, SEM micrographs at low magnifications were analyzed (grey bars) using the software Linear Intercept, then the cumulative values were calculated (solid lines).

Figure 3: Determination of the proliferation of human $U_{2} O$ s osteosarcoma cells 1 to 3 days after seeding in the scaffolds.

To evaluate for cell proliferation in the scaffolds, $\mathrm{U}_{2}$ Os cells were seeded onto one of each of the three scaffolds (S1, S2, S3) and culture was performed for $24 \mathrm{~h}$. AlamarBlue was added to the cells-scaffolds and fluorescence measured after $45 \mathrm{~min}$. Then, fresh medium was added and culture continued and the process was repeated after $48 \mathrm{~h}$ and $72 \mathrm{~h}$ of cell culture in the scaffolds, allowing the same cell-scaffold system to be sequentially analyzed on day 1, day 2 and day 3. scaffold S1; $\square$ scaffold S2; $\Delta$ scaffold S3.

Figure 4: SEM micrographs of human osteosarcoma cells inside the scaffolds.

A. Human SaOs (upper panels) and $\mathrm{U}_{2} \mathrm{Os}$ (lower panels) osteosarcoma cells were grown in scaffold S1 (S1), scaffold S2 (S2) or scaffold S3 (S3) for, respectively, 1 day or 4 days. After fixation in paraformaldehyde, the scaffolds were split and SEM pictures of the cells inside the scaffolds taken, showing that the cells adhered and spread onto the ceramic materials. White 
arrows indicate the cells.

B. Human $\mathrm{U}_{2} \mathrm{Os}$ osteosarcoma cells were unidirectionally (red arrow) seeded on the top of scaffold and grown for 4 days in scaffold S3. Then the scaffold was fixed in paraformaldehyde, split in the middle and the fracture section was scanned by SEM. Isolated cells (labeled 1-5) are shown at higher magnification in panels 1-5. For improved viewing, the cell shapes are surrounded by a white line.

Figure 5: Expression of collagen I, alkaline phosphatase activity and calcium deposits by the the human bone-derived cells.

A. Human cells (skin fibroblasts, fetal osteoblasts (FSOS), and osteosarcoma cells (SaOs, $\mathrm{U}_{2} \mathrm{Os}$ ) were grown to confluence in Petri dishes and extracted. Cell extracts were submitted to western blotting experiments using an anti-human collagen I antibody, and loading was controlled using an anti-human $\alpha$-tubulin antibody. When the cells were grown in differentiating medium for 7 to 14 days, no induction of collagen I expression by $\mathrm{U}_{2} \mathrm{Os}$ and SaOs cells and no further enhancement of collagen I expression by FsOs cells by differentiation medium was observed (not shown).

B. Alkaline phosphatase activity (U/mg protein) was determined in human fetal osteoblasts (FsOs), and osteosarcoma cells (SaOs, U2Os) grown either in standard or in differentiating culture medium (diff) for 10 days. Means of triplicate wells \pm sd were calculated. Experiments were repeated 3 times with similar information. No further enhancement of alkaline phosphatase activity by FsOs cells by differentiation medium was observed for longer culture in differentiation medium (not shown).

C. Kossa staining of calcium deposits (black staining, arrows) in terminally differentiated, non-proliferating human fetal osteoblasts. Cell cytoplasms are stained light pink and cell nuclei dark pink. 
Figure 6: Human fetal osteoblasts grown in scaffold S3 are retained, proliferate and are metabolically active in the scaffolds for at least 6 weeks.

A. Human fetal osteoblasts were prelabeled with $\left[{ }^{3} \mathrm{H}\right]$-thymidine, then grown in the scaffolds for 2 or 6 days. Radioactivity was quantified in extracts of the cells in the scaffolds (dark grey), associated to the cells at the bottom of the wells (light grey) and in the soluble culture media (black). The experiments were repeated twice, with comparable information.

B. Human fetal osteoblasts were grown in scaffolds S3 for 6 days. After fixation in paraformaldehyde, the scaffolds were split and SEM pictures of the cells inside the scaffolds taken, showing that the cells adhered and moved into the ceramic materials, spanning across the pores in the selected SEM picture.

C. Human fetal osteoblasts were seeded on scaffold S3 and grown in culture medium. After 7, 14, 21 and 38 days of osteoblast culture in the scaffolds, WST-1 was added to the culture medium bathing the scaffolds (2-3 scaffolds per time-point) and absorbance kinetically measured for $30 \mathrm{~min}$. Metabolically active cells reduce WST1 to a soluble red compound whose absorbance is directly proportional to the number of alive cells. Differences in absorbance between 30 and 0 min were determined, and means \pm sd calculated.

D. Human fetal osteoblasts were seeded on the top of scaffolds S3 and grown for 6 weeks in the scaffolds. MTT was added to the culture medium bathing the scaffolds for $3 \mathrm{~h}$, the scaffolds were washed and fixed in paraformaldehyde, and the upper and lower sides of the scaffolds were photographed. Metabolically active cells reduce MTT to a violet precipitate. Scaffolds without cells but exposed to MTT do not color in violet. In scaffold S3, cells can be found on both sides of the scaffolds. Experiments performed with scaffolds S1 in the same conditions for comparison demonstrate the presence of cells only on the up side of these scaffolds. 
Figure 7: SEM micrographs of human fetal osteoblasts inside the scaffolds.

Human fetal osteoblasts were grown for 6 weeks in scaffold S3. After fixation in paraformaldehyde, the scaffold was split in the middle and the fracture section was scanned by SEM and SEM pictures of the cells inside the scaffolds taken, showing that the cells adhered and spread onto the ceramic materials at all levels of the materials.

a) cross-section of a S3 scaffold, unidirectionally seeded (seeding direction from top to bottom) with fetal osteoblasts and cultured in the scaffolds for 6 weeks; bar $=200 \mu \mathrm{m}$.

b) close ups of the cells indicated by a number (1 to 9) in (a). For improved viewing, the cells in the scaffolds were outlined with white lines except in panels b6 and b7 where most of the area is covered by cells; bars $=5 \mu \mathrm{m}$.

Figure 8. Enhancement of rapid adhesion of the human fetal osteoblasts by clickfunctionalization of the scaffolds.

A: Disks of scaffolds functionalized with 0,5 , or $10 \mu \mathrm{M}$ of compound 5 were incubated with FtOs for $1 \mathrm{~h}$, then the cells were stained and photographed.

B: The quantification of the number of adhered cells was performed by analysis of stereomicroscopy pictures. Results are the mean \pm sd of triplicates of three independent experiments. The number of cells adhering to the bio-ceramics disks was compared among unfunctionalized scaffolds $(0 \mu \mathrm{M})$ and scaffolds functionalized with compound 5 ( $5 \mu \mathrm{M}$ or 10 $\mu \mathrm{M})$ using a Student's $t$-test : *** $: \mathrm{p}<0.001$. The correlation coefficient was caculated between the number of adhered cells on scaffolds functionalized with $5 \mu \mathrm{M}$ and $10 \mu \mathrm{M}$ of compound $5: r=1.00$. 


\section{Figures}

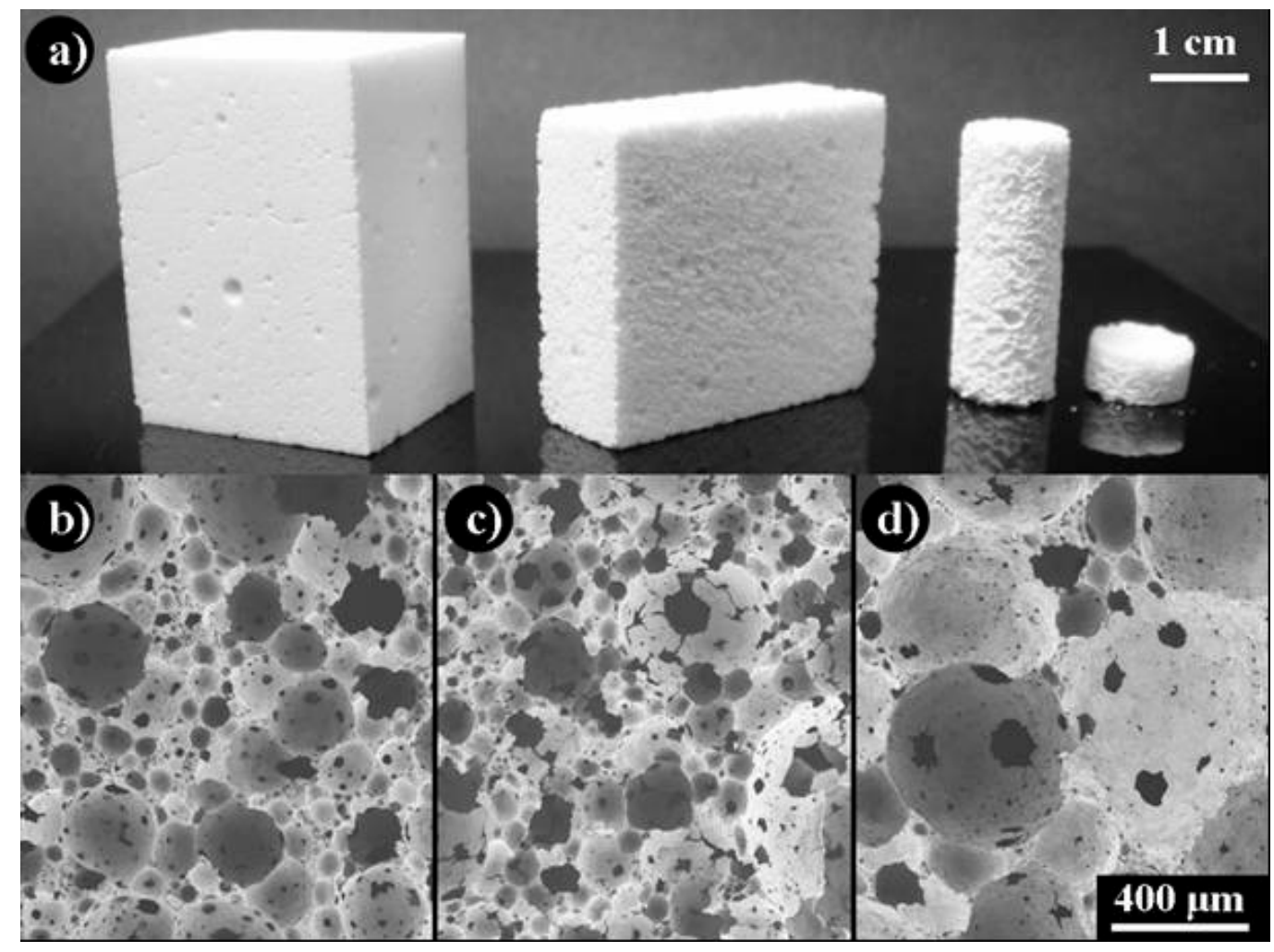

Figure 1: Macroscopic and microscopic aspect of the scaffolds.

Upper panel: a) macrophotographs of the three different scaffold materials (from left to right: scaffold S1, scaffold S2 and two pictures of scaffold S3);

Lower panels: SEM micrographs of b) scaffold S1; c) scaffold S2; d) scaffold S3. 


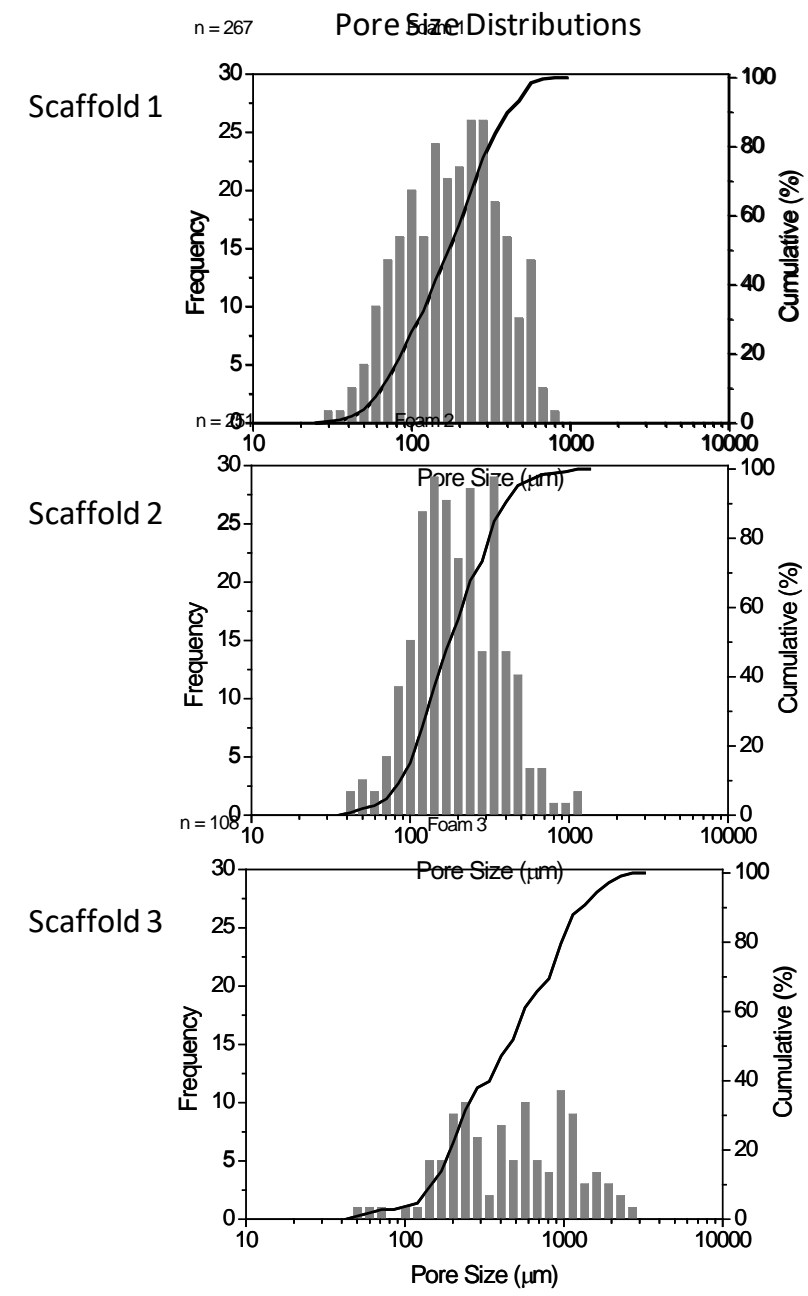

$\mathrm{n}=119$ Pore-Openings Size Distributions
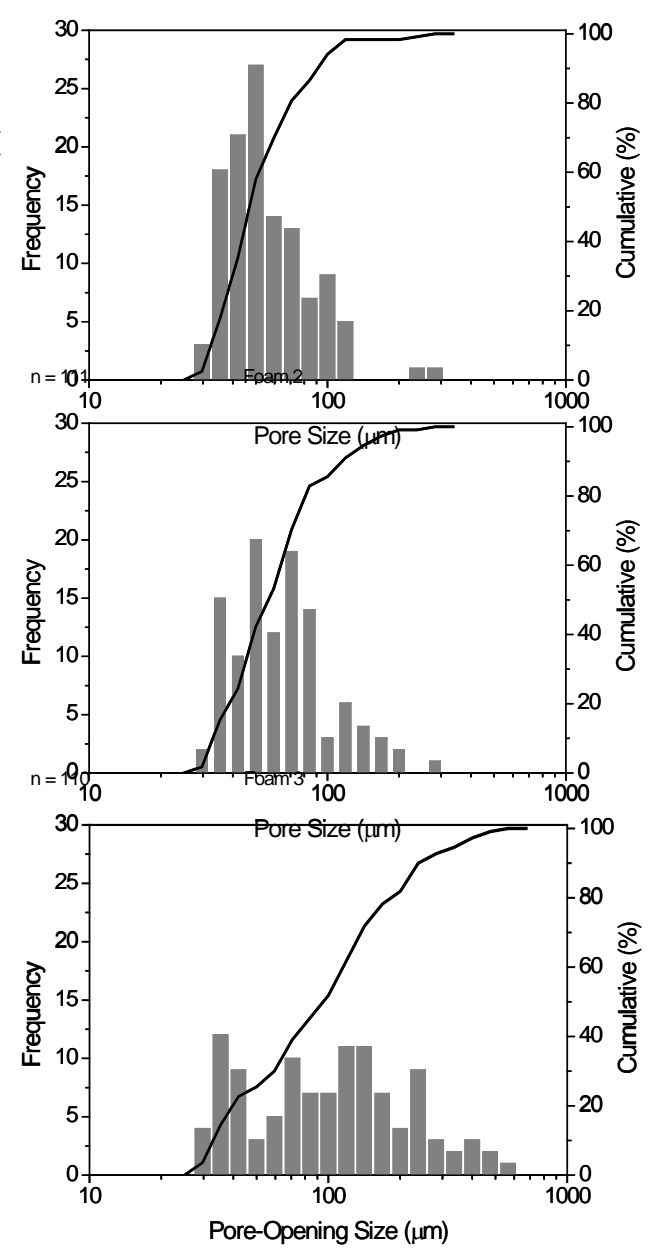

Figure 2: Size distribution of the pores and pore openings for the 3 different scaffolds.

To define the diameters of the pores and pore-openings, SEM micrographs at low magnifications were analyzed (grey bars) using the software Linear Intercept, then the cumulative values were calculated (solid lines). 


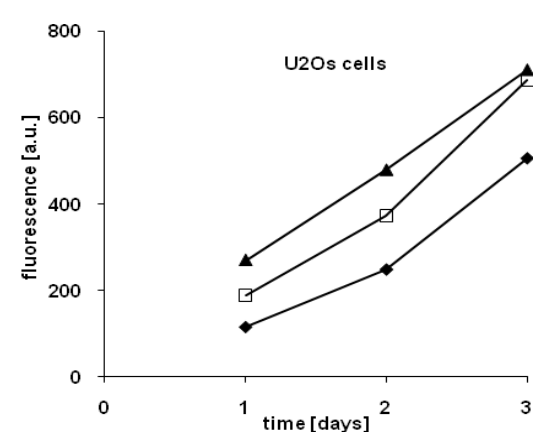

Figure 3: Determination of the proliferation of human $U_{2} O$ s osteosarcoma cells 1 to 3 days after seeding in the scaffolds.

To evaluate for cell proliferation in the scaffolds, $\mathrm{U}_{2}$ Os cells were seeded onto one of each of the three scaffolds (S1, S2, S3) and culture was performed for $24 \mathrm{~h}$. AlamarBlue was added to the cells-scaffolds and fluorescence measured after $45 \mathrm{~min}$. Then, fresh medium was added and culture continued and the process was repeated after $48 \mathrm{~h}$ and $72 \mathrm{~h}$ of cell culture in the scaffolds, allowing the same cell-scaffold system to be sequentially analyzed on day 1, day 2 and day 3. scaffold S1; $\square$ scaffold S2; $\Delta$ scaffold S3. 
A

SaOs cells, 1 day
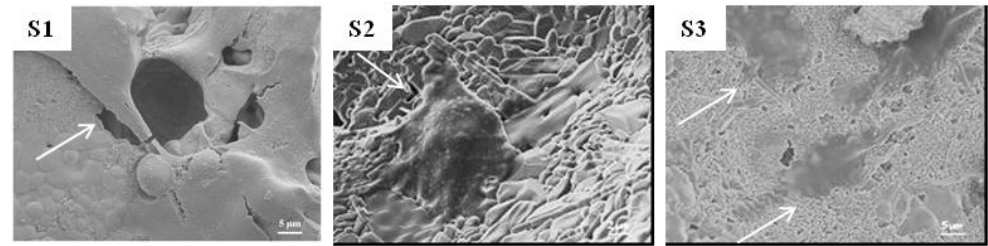

$\mathrm{U}_{2}$ Os cells, 4 days

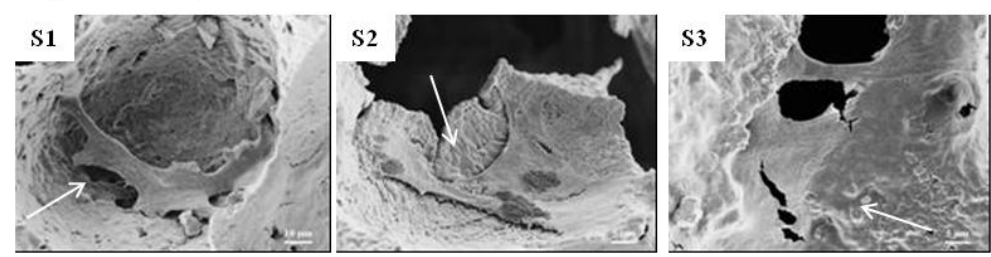

B

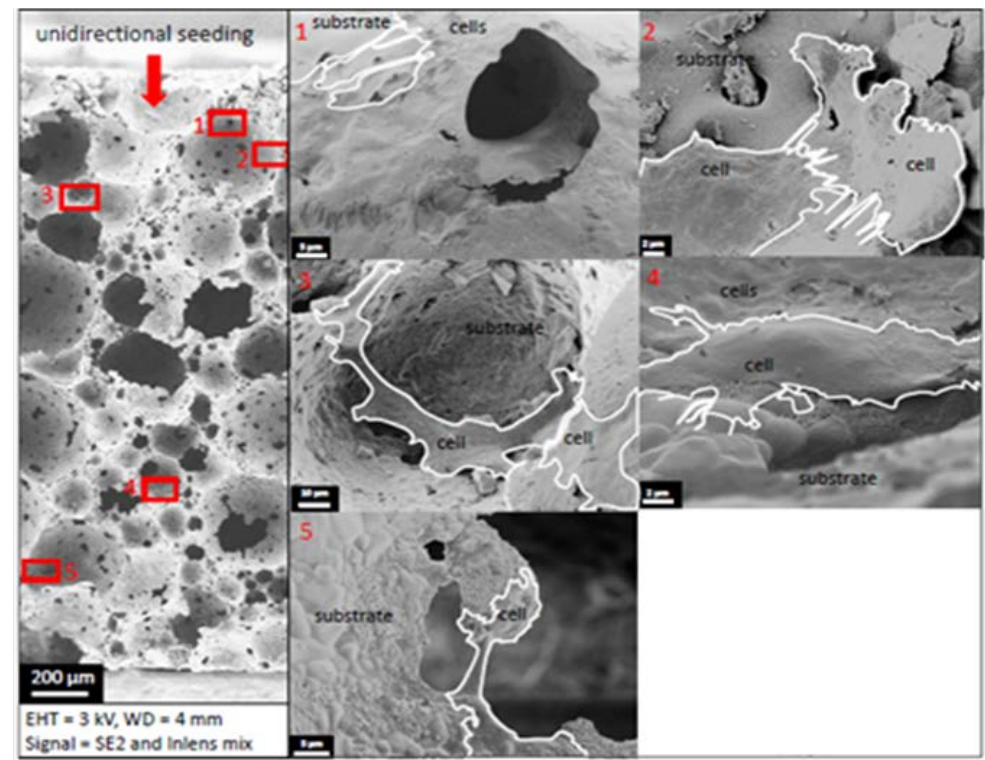

Figure 4: SEM micrographs of human osteosarcoma cells inside the scaffolds.

A. Human $\mathrm{SaOs}$ (upper panels) and $\mathrm{U}_{2} \mathrm{Os}$ (lower panels) osteosarcoma cells were grown in scaffold S1 (S1), scaffold S2 (S2) or scaffold S3 (S3) for, respectively, 1 day or 4 days. After fixation in paraformaldehyde, the scaffolds were split and SEM pictures of the cells inside the scaffolds taken, showing that the cells adhered and spread onto the ceramic materials. White arrows indicate the cells.

B. Human $\mathrm{U}_{2} \mathrm{Os}$ osteosarcoma cells were unidirectionally (red arrow) seeded on the top of scaffold and grown for 4 days in scaffold S3. Then the scaffold was fixed in 
paraformaldehyde, split in the middle and the fracture section was scanned by SEM. Isolated cells (labeled 1-5) are shown at higher magnification in panels 1-5. For improved viewing, the cell shapes are surrounded by a white line. 
A

B
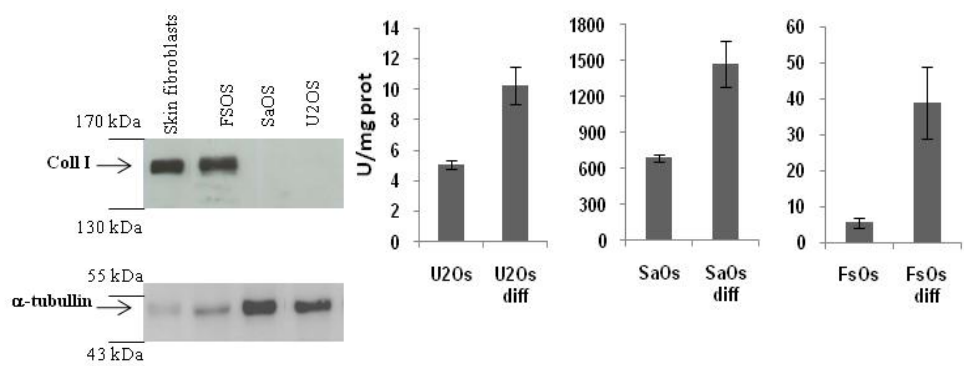

C

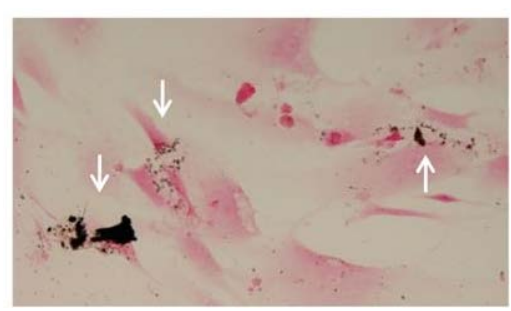

Figure 5: Expression of collagen I, alkaline phosphatase activity and calcium deposits by the human bone-derived cells.

A. Human cells (skin fibroblasts, fetal osteoblasts (FSOS), and osteosarcoma cells (SaOs, $\left.\mathrm{U}_{2} \mathrm{Os}\right)$ ) were grown to confluence in Petri dishes and extracted. Cell extracts were submitted to western blotting experiments using an anti-human collagen I antibody, and loading was controlled using an anti-human $\alpha$-tubulin antibody. When the cells were grown in differentiating medium for 7 to 14 days, no induction of collagen I expression by $\mathrm{U}_{2} \mathrm{Os}$ and SaOs cells and no further enhancement of collagen I expression by FsOs cells by differentiation medium was observed (not shown).

B. Alkaline phosphatase activity (U/mg protein) was determined in human fetal osteoblasts (FsOs), and osteosarcoma cells (SaOs, U2Os) grown either in standard or in differentiating culture medium (diff) for 10 days. Means of triplicate wells \pm sd were calculated. Experiments were repeated 3 times with similar information. No further enhancement of alkaline phosphatase activity by FsOs cells by differentiation medium was observed for longer culture in differentiation medium (not shown).

C. Kossa staining of calcium deposits (black staining, arrows) in terminally differentiated, 
non-proliferating human fetal osteoblasts. Cell cytoplasms are stained light pink and cell nuclei dark pink. 
A

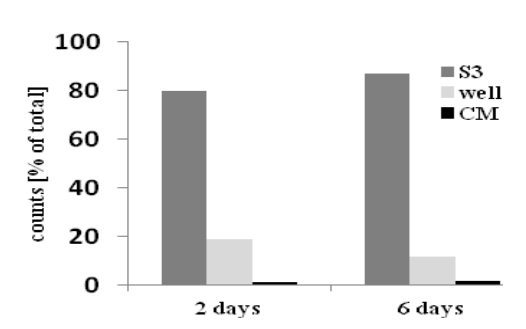

C

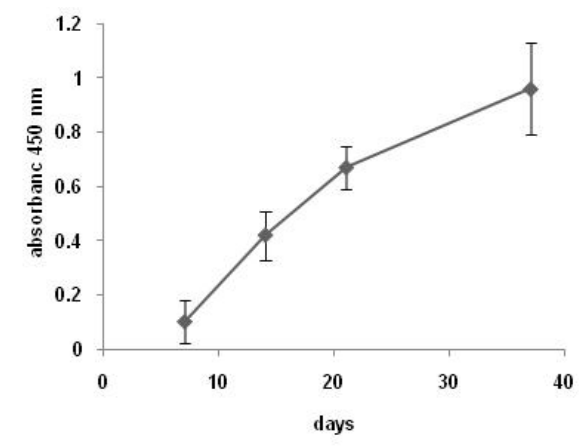

B

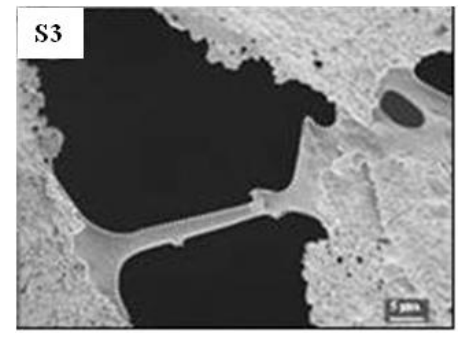

D

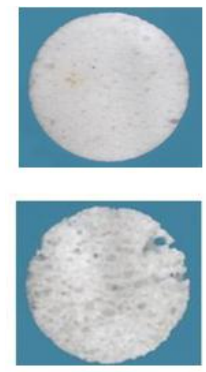

no cells

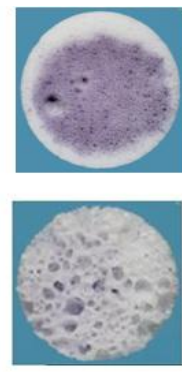

up side
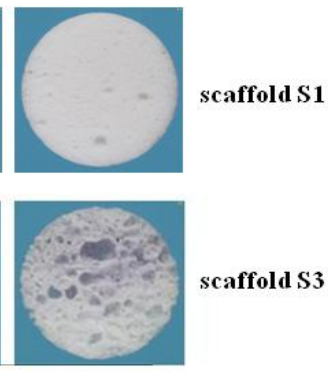

down side

Figure 6: Human fetal osteoblasts grown in scaffold S3 are retained, proliferate and are metabolically active in the scaffolds for at least 6 weeks.

A. Human fetal osteoblasts were prelabeled with $\left[{ }^{3} \mathrm{H}\right]$-thymidine, then grown in the scaffolds for 2 or 6 days. Radioactivity was quantified in extracts of the cells in the scaffolds (dark grey), associated to the cells at the bottom of the wells (light grey) and in the soluble culture media (black). The experiments were repeated twice, with comparable information.

B. Human fetal osteoblasts were grown in scaffolds S3 for 6 days. After fixation in paraformaldehyde, the scaffolds were split and SEM pictures of the cells inside the scaffolds taken, showing that the cells adhered and moved into the ceramic materials, spanning across the pores in the selected SEM picture.

C. Human fetal osteoblasts were seeded on scaffold S3 and grown in culture medium. After 7, 14, 21 and 38 days of osteoblast culture in the scaffolds, WST-1 was added to the culture medium bathing the scaffolds (2-3 scaffolds per time-point) and absorbance kinetically measured for $30 \mathrm{~min}$. Metabolically active cells reduce WST1 to a soluble red compound whose absorbance is directly proportional to the number of alive cells. Differences in 
absorbance between 30 and 0 min were determined, and means \pm sd calculated.

D. Human fetal osteoblasts were seeded on the top of scaffolds S3 and grown for 6 weeks in the scaffolds. MTT was added to the culture medium bathing the scaffolds for $3 \mathrm{~h}$, the scaffolds were washed and fixed in paraformaldehyde, and the upper and lower sides of the scaffolds were photographed. Metabolically active cells reduce MTT to a violet precipitate. Scaffolds without cells but exposed to MTT do not color in violet. In scaffold S3, cells can be found on both sides of the scaffolds. Experiments performed with scaffolds S1 in the same conditions for comparison demonstrate the presence of cells only on the up side of these scaffolds. 
a)

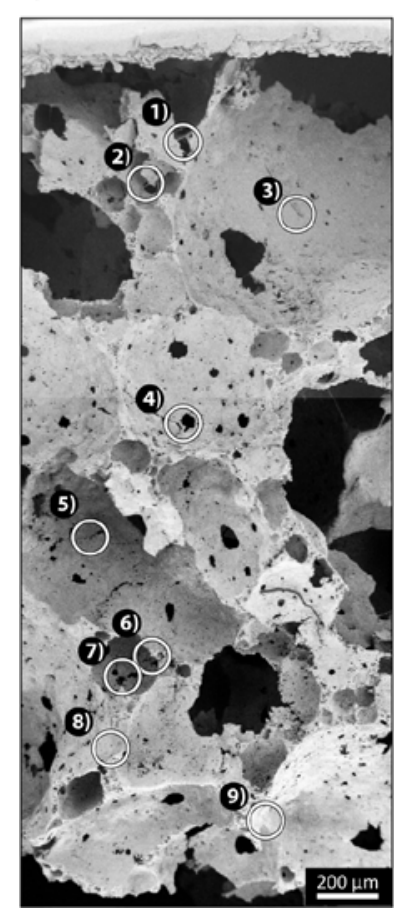

b)

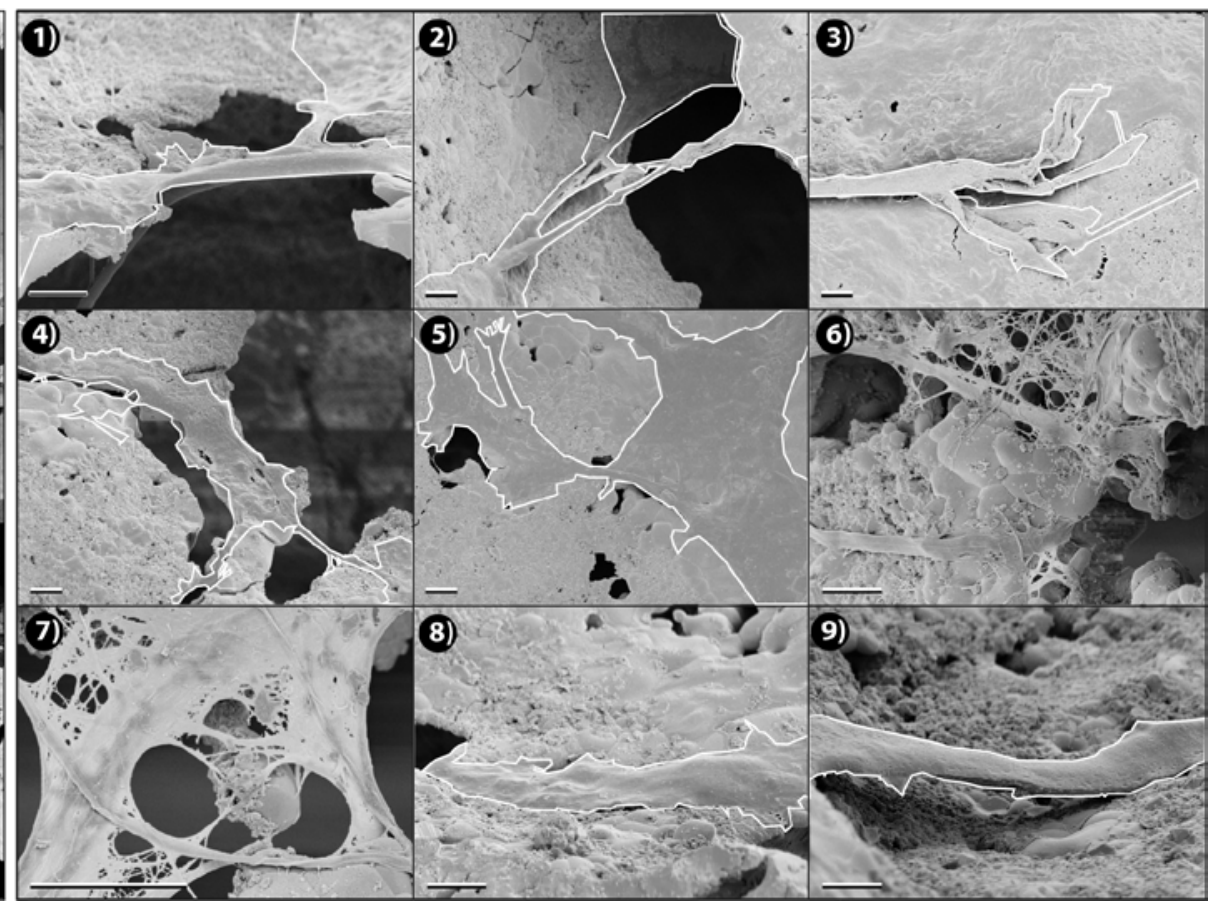

Figure 7: SEM micrographs of human fetal osteoblasts inside the scaffolds.

Human fetal osteoblasts were grown for 6 weeks in scaffold S3. After fixation in paraformaldehyde, the scaffold was split in the middle and the fracture section was scanned by SEM and SEM pictures of the cells inside the scaffolds taken, showing that the cells adhered and spread onto the ceramic materials at all levels of the materials.

a) cross-section of a S3 scaffold, unidirectionally seeded (seeding direction from top to bottom) with fetal osteoblasts and cultured in the scaffolds for 6 weeks; bar $=200 \mu \mathrm{m}$.

b) close ups of the cells indicated by a number (1 to 9) in (a). For improved viewing, the cells in the scaffolds were outlined with white lines except in panels b6 and b7 where most of the area is covered by cells; bars $=5 \mu \mathrm{m}$. 
A
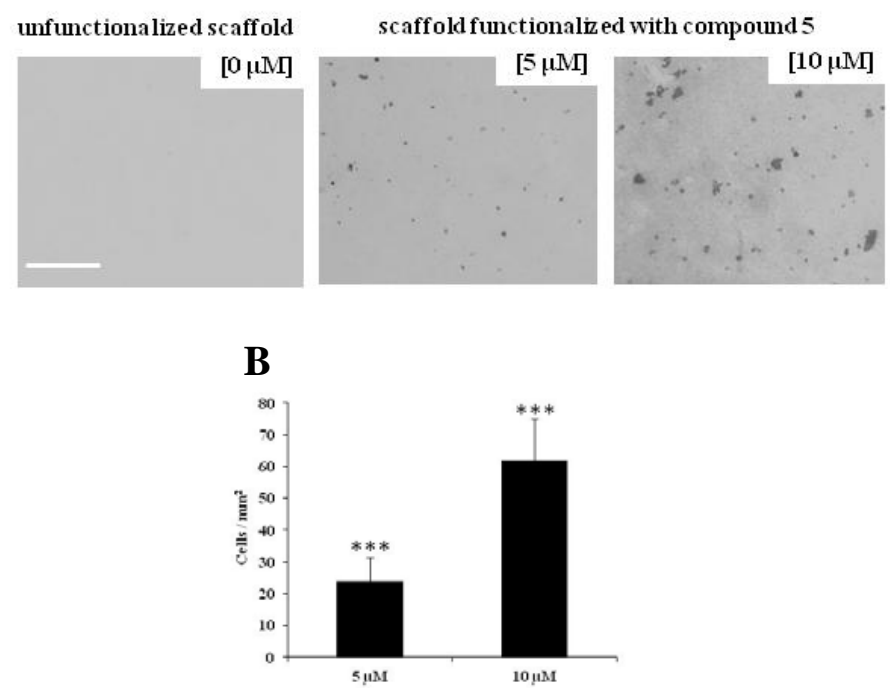

Figure 8. Enhancement of rapid adhesion of human fetal osteoblasts by clickfunctionalization of the scaffolds.

A: Disks of scaffolds functionalized with 0,5 , or $10 \mu \mathrm{M}$ of compound 5 were incubated with FtOs for $1 \mathrm{~h}$, then the cells were stained and photographed.

B: The quantification of the number of adhered cells was performed by analysis of stereomicroscopy pictures. Results are the mean \pm sd of triplicates of three independent experiments. The number of cells adhering to the bio-ceramics disks was compared among unfunctionalized scaffolds $(0 \mu \mathrm{M})$ and scaffolds functionalized with compound 5 ( $5 \mu \mathrm{M}$ or 10 $\mu \mathrm{M})$ using a Student's $t$-test : *** $: \mathrm{p}<0.001$. The correlation coefficient was caculated between the number of adhered cells on scaffolds functionalized with $5 \mu \mathrm{M}$ and $10 \mu \mathrm{M}$ of compound $5: \mathrm{r}=1.00$. 
Foam scaffolds of calcium alumina permissive for trans-scaffold migration and proliferation of primary human fetal osteoblasts were developed and characterized as permanent implants for bone repair.

\section{TOC Graphic}

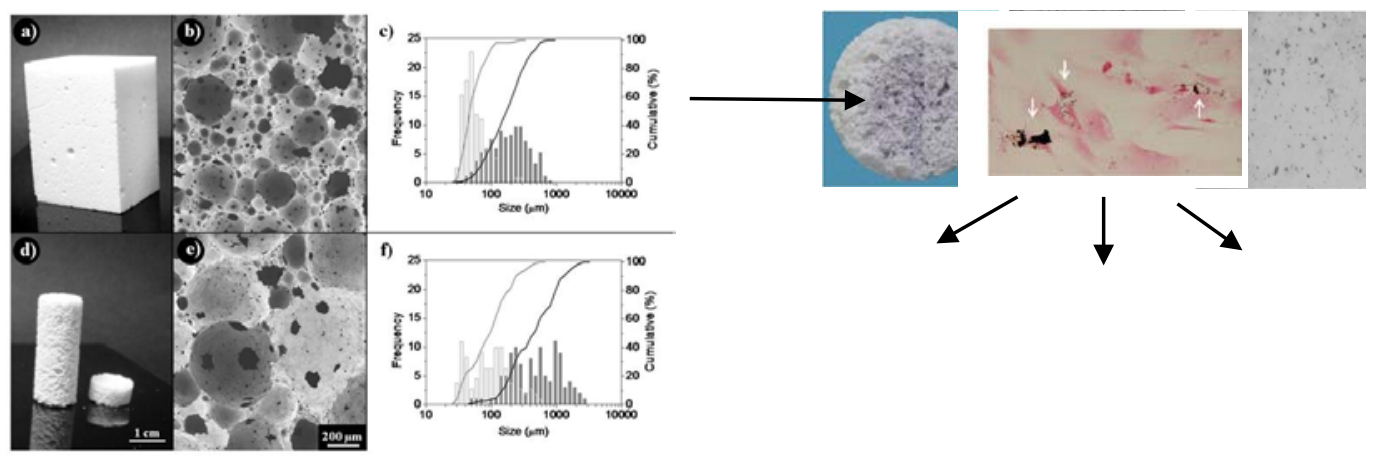

